\title{
Initiators of Classical and Lectin Complement Pathways Are Differently Engaged after Traumatic Brain Injury-Time-Dependent Changes in the Cortex, Striatum, Thalamus and Hippocampus in a Mouse Model
}

\author{
Agata Ciechanowska ${ }^{1}$, Katarzyna Ciapała ${ }^{1}$, Katarzyna Pawlik ${ }^{1}$, Marco Oggioni ${ }^{2}$ (D), Domenico Mercurio ${ }^{2}$ D, \\ Maria-Grazia De Simoni ${ }^{2}$ and Joanna Mika ${ }^{1, *(D)}$ \\ 1 Department of Pain Pharmacology, Maj Institute of Pharmacology, Polish Academy of Sciences, \\ 31-343 Krakow, Poland; ciechan@if-pan.krakow.pl (A.C.); kat.ciapala@gmail.com (K.C.); \\ pawlik@if-pan.krakow.pl (K.P.) \\ 2 Department of Neuroscience, Istituto di Ricerche Farmacologiche Mario Negri-IRCCS, 20156 Milan, Italy; \\ marco.oggioni@marionegri.it (M.O.); domenico.mercurio@marionegri.it (D.M.); \\ mariagrazia.desimoni@marionegri.it (M.-G.D.S.) \\ * Correspondence: joamika@if-pan.krakow.pl; Tel.: +48-12-6623240
}

\section{check for}

updates

Citation: Ciechanowska, A.; Ciapała, K.; Pawlik, K.; Oggioni, M.; Mercurio, D.; De Simoni, M.; Mika, J. Initiators of Classical and Lectin Complement Pathways Are Differently Engaged after Traumatic Brain Injury-TimeDependent Changes in the Cortex, Striatum, Thalamus and Hippocampus in a Mouse Model. Int. J. Mol. Sci. 2021, 22, 45. https:/ /dx.doi.org/10.3390/ijms 22010045

Received: 7 December 2020 Accepted: 19 December 2020

Published: 22 December 2020

Publisher's Note: MDPI stays neutral with regard to jurisdictional claims in published maps and institutional affiliations.

Copyright: (c) 2020 by the authors. Licensee MDPI, Basel, Switzerland. This article is an open access article distributed under the terms and conditions of the Creative Commons Attribution (CC BY) license (https: / / creativecommons.org / licenses/by/4.0/).

\begin{abstract}
The complement system is involved in promoting secondary injury after traumatic brain injury (TBI), but the roles of the classical and lectin pathways leading to complement activation need to be clarified. To this end, we aimed to determine the ability of the brain to activate the synthesis of classical and lectin pathway initiators in response to TBI and to examine their expression in primary microglial cell cultures. We have modeled TBI in mice by controlled cortical impact (CCI), a clinically relevant experimental model. Using Real-time quantitative polymerase chain reaction (RT-qPCR) we analyzed the expression of initiators of classical the complement component $1 \mathrm{q}, 1 \mathrm{r}$ and $1 \mathrm{~s}(\mathrm{C} 1 q, \mathrm{C} 1 \mathrm{r}$, and $\mathrm{C} 1 \mathrm{~s})$ and lectin (mannose binding lectin $\mathrm{A}$, mannose binding lectin $\mathrm{C}$, collectin 11, ficolin $A$, and ficolin $B$ ) complement pathways and other cellular markers in four brain areas (cortex, striatum, thalamus and hippocampus) of mice exposed to CCI from $24 \mathrm{~h}$ and up to 5 weeks. In all murine ipsilateral brain structures assessed, we detected long-lasting, time- and areadependent significant increases in the mRNA levels of all classical (C1q, C1s, C1r) and some lectin (collectin 11, ficolin A, ficolin B) initiator molecules after TBI. In parallel, we observed significantly enhanced expression of cellular markers for neutrophils (Cd177), T cells (Cd8), astrocytes (glial fibrillary acidic protein-GFAP), microglia/macrophages (allograft inflammatory factor 1-IBA-1), and microglia (transmembrane protein 119-TMEM119); moreover, we detected astrocytes (GFAP) and microglia/macrophages (IBA-1) protein level strong upregulation in all analyzed brain areas. Further, the results obtained in primary microglial cell cultures suggested that these cells may be largely responsible for the biosynthesis of classical pathway initiators. However, microglia are unlikely to be responsible for the production of the lectin pathway initiators. Immunofluorescence analysis confirmed that at the site of brain injury, the $\mathrm{C} 1 \mathrm{q}$ is localized in microglia/macrophages and neurons but not in astroglial cells. In sum, the brain strongly reacts to TBI by activating the local synthesis of classical and lectin complement pathway activators. Thus, the brain responds to TBI with a strong, widespread and persistent upregulation of complement components, the targeting of which may provide protection in TBI.
\end{abstract}

Keywords: complement component 1q (C1q); complement component 1s (C1s); complement component 1r (C1r); collectin 11; ficolin A; ficolin B; mannose binding lectin A (MBL-A); mannose binding lectin C (MBL-C); cortex; striatum; thalamus; hippocampus 


\section{Introduction}

Traumatic brain injury (TBI) persists as a leading cause of disability and mortality affecting the worldwide community. TBI is known to be associated with primary mechanical damage that results in secondary pathogenic cellular cascades, activated within minutes following injury, that interacts in a complex network, which leads to cell death or recovery [1]. In patients surviving TBI, this secondary injury cascade, which is closely related to activation of the inflammatory response, is believed to be responsible for the evolution of the brain damage [2,3]. Not enough is known about the cellular and molecular changes occurring during the secondary damage, which evolves over days after the injury. Gaining knowledge about these changes will be very important for development of novel pharmacological and therapeutic interventions [4].

The complement system is a powerful effector tool of innate and adaptive immunity. In the brain, the complement system is known to subserve multiple functions, including regulation of synaptic pruning during development, control of homeostatic functions in the uninjured brain, and coordination of the inflammatory response following injury. There are three pathways leading to full activation of the complement cascade: the classical, the alternative, and the lectin pathway, each responding to specific danger signals and characterized by specific initiators and enzymes. The classical pathway is activated following the binding of the $\mathrm{C} 1 \mathrm{q}-\mathrm{C} 1 \mathrm{~s}-\mathrm{C} 1 \mathrm{r}$ complex to antigen-antibody complexes or directly to specific molecules (i.e., beta-amyloid, $\mathrm{C}$ reactive protein, DNA, and apoptotic bodies). The lectin pathway activator molecules include different pattern recognition molecules, such as mannose binding lectins (MBLs, found in rodents in two isoforms: A and C) and collectin-11, or by ficolins (found in rodents in two isoforms: A and B), which bind to high-density arrays of mannose, fucose, and N-acetylated sugars present on the surface of injured cells or pathogens. Spontaneous hydrolysis of circulating C3 (tick-over process) into $\mathrm{C} 3\left(\mathrm{H}_{2} \mathrm{O}\right)$ on cellular surfaces acts as activator of the alternative pathway. The three pathways converge into a common pathway, resulting in the formation of the terminal C5b-9 complement complex the effector of cell lysis. A few fragments which are produced along the cascade, such as $\mathrm{C} 3 \mathrm{~b}, \mathrm{C} 4 \mathrm{~b}$, and $\mathrm{C} 5 \mathrm{~b}$, possess direct inflammatory properties and act as opsonins, inducing an overactivation of the phagocytic response. In addition, the complement components coordinate an innate and adaptive immune reaction by interacting with multiple immune cells [5]. Complement activation results in the production of anaphylatoxins ( $\mathrm{C} 3 \mathrm{a}$ and $\mathrm{C} 5 \mathrm{a}$ ), powerful mediators of inflammation, which causes recruitment and activation of different cells, including neutrophils, $\mathrm{T}$ cells and macrophages. Neutrophils, which are the most abundant leukocytes in circulation, are also the first-line immune cells that reach the sites of injury [6,7]. Brain Cd8+ T cells may impact prolonged motor deficits and myelin pathology. Moreover, TBI-related neuroinflammation is also characterized by changes in the morphology and number of oligodendrocytes, astrocytes and microglia/macrophages [6-9]. Recently, clinical studies have supported these data, showing the maintenance of sustained astrocytes and microglial activation in the brains of TBI patients [10,11].

The complement system contributes to secondary injury in TBI [5,12], but while it is well established that injury activates the complement cascade as a systemic response and that circulating complement components get into the brain through the injured blood-brain barrier (BBB), little is known about local activation. Therefore, the purpose of our research was to determine the ability of the brain to activate the synthesis of classical and lectin pathway initiators in response to TBI and to examine their expression in different types of brain cells. Based on previous experiments, we performed controlled cortical impact (CCI) in mice, which is a clinically relevant experimental model of TBI that causes a large inflammatory response and drives the progression of brain injury $[3,13,14]$. We examined concomitant spatiotemporal changes occurring at the mRNA and/or protein levels of classical (C1q, $\mathrm{C} 1 \mathrm{~s}$, and C1r) and lectin (MBL-A, MBL-C, collectin 11, ficolin A, and ficolin B) complement factors as well as cellular markers of neutrophils (Cd177), T cells (Cd8), oligodendrocytes (oligodendrocyte transcription factor 2-Olig2), astrocytes (GFAP), microglia/macrophages (IBA-1), 
and microglia (TMEM119) in various brain structures (cortex, striatum, thalamus, and hippocampus) after TBI. Moreover, we used confocal microscopy to study the C1q cellular localization in the contused cortex after TBI. We also studied the effect of lipopolysaccharide (LPS), an inflammatory stimulus, on the levels of a few classical and lectin pathway components in primary microglial cell cultures.

\section{Results}

2.1. Time-Dependent Study of Cd177, Cd8 and Olig2 mRNA Expression in the Cortex, Striatum, Thalamus, and Hippocampus after TBI in Mice

The elevated mRNA expression of $C d 177$ (a cellular marker of neutrophils) was observed in the cortex, striatum, and hippocampus (Figure 1A,B,D). In the cortex and striatum, Cd177 upregulation began $24 \mathrm{~h}$ after TBI, was the highest on the 4 th day and remained elevated until the 7th day after traumatic brain injury when compared to that of sham-operated animals (Figure 1A,B).
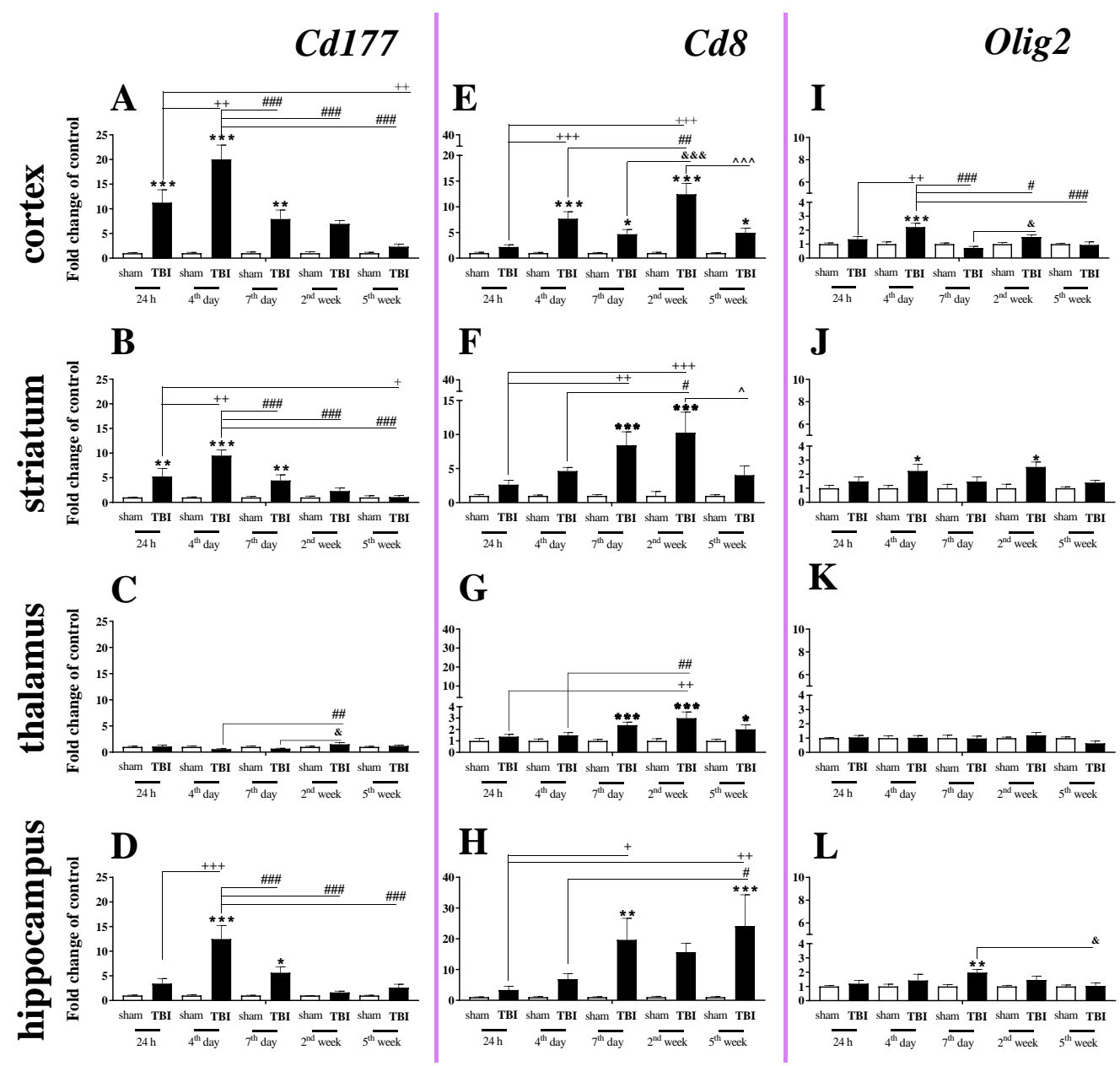

Figure 1. (A-L). The mRNA expression changes of $C d 177, C d 8$, and Olig2 in the cortex, striatum, thalamus, and hippocampus of TBI compared to sham-injured animals at different time points ( $24 \mathrm{~h}-5$ weeks). The data are given as fold changes relative to the control as mean \pm SEM (standard error of the mean) (sham groups, $n=5-8$; TBI groups, $n=4-8$ ). ${ }^{*} p<0.05 ;{ }^{* *} p<0.01$; ${ }^{* * *} p<0.001$ show differences considered statistically significant between the sham and TBI groups, $+p<0.05 ;++p<0.01 ;+++p<0.001$ show differences considered statistically significant comparing to the $24 \mathrm{~h}$ TBI group; $\#<0.05$; \# $p<0.01$; \#\# $p<0.001$ show differences considered statistically significant comparing to the 4 th day TBI group; \& $p<0.05 ; \& \& \& p<0.001$ show differences considered statistically significant when comparing to the 7th day TBI group; ${ }^{\wedge} p<0.05 ;{ }^{\wedge} p<0.001$ show differences considered statistically significant comparing to the 2 weeks TBI group as estimated by two-way ANOVA followed by Bonferroni's post hoc test. 
In the hippocampus, $C d 177$ upregulation began and reached a peak 4 days after brain injury and then decreased after day 7. We did not observe any changes in expression of $C d 177$ in the thalamus (Figure 1C). For the mRNA expression of $C d 177$, the two-way ANOVA confirmed a significant interaction between the considered time points and TBI for the cortex $\left(\mathrm{F}_{4,55}=9.34 ; p<0.0001\right)($ Figure $1 \mathrm{~A})$, striatum $\left(\mathrm{F}_{4,55}=7.88 ; p<0.0001\right)$ (Figure $\left.1 \mathrm{~B}\right)$, and hippocampus $\left(\mathrm{F}_{4,52}=7.47 ; p<0.0001\right)$ (Figure 1D).

Upregulation of $C d 8$ mRNA expression (a cellular marker of T cells) was observed in all studied structures. The changes began in the cortex 4 days after injury and in the striatum and hippocampus on the 7th day. When comparing to the mRNA level of sham-operated animals, the highest value was observed 2 weeks after brain injury in cortex and striatum and 5 weeks after injury in the hippocampus. In the cortex and hippocampus, $C d 8$ mRNA remained elevated until the 5th week, which was the last time point (Figure 1E,H). For the mRNA expression of $C d 8$, the two-way ANOVA confirmed a significant interaction between the considered time points and TBI in the cortex $\left(\mathrm{F}_{4,55}=8.76 ; p<0.0001\right)$ (Figure 1E), striatum $\left(\mathrm{F}_{4,55}=3.52\right.$; $p=0.0125$ ) (Figure 1F), and hippocampus $\left(\mathrm{F}_{4,53}=2.76 ; p=0.0372\right)$ (Figure $\left.1 \mathrm{H}\right)$. Moreover, after TBI, we observed upregulation of $C d 8$ in the thalamus (Figure 1G) between the 7 th day and 5th week when compared to that in sham animals, according to Bonferroni's post hoc analysis.

The expression of Olig2 (a marker of oligodendrocytes) was significantly elevated in the cortex, and the upregulation was observed 4 days after injury. For the mRNA expression of Olig2 in the cortex, two-way ANOVA confirmed a significant interaction between the considered time points and TBI $\left(\mathrm{F}_{4,54}=7.06 ; p=0.0001\right)$ (Figure $\left.1 \mathrm{I}\right)$. Moreover, we observed upregulation of Olig2 in the striatum (Figure 1J) on the 4th day and 2nd week and hippocampus on the day 7th after TBI when compared to that in sham animals, according to Bonferroni's post hoc analysis. No changes in mRNA expression were obtained in the thalamus.

\subsection{Time-Dependent Study of GFAP, IBA-1 and TMEM119 mRNA Expression in the Cortex, Striatum, Thalamus, and Hippocampus after TBI in Mice}

GFAP (a marker of astroglia) expression was elevated in all studied brain structures, and the strongest changes were observed in the cortex, striatum, and hippocampus 4-7 days after injury. In the cortex, the GFAP upregulation began $24 \mathrm{~h}$ after injury, reached the highest value on day 4 and then significantly declined until the 5th week following injury (Figure 2A). For the striatum and hippocampus, GFAP upregulation also started $24 \mathrm{~h}$ after TBI and reached a maximum on the same day. For the mRNA expression of GFAP, two-way ANOVA confirmed a significant interaction between the considered time points and TBI in the cortex $\left(\mathrm{F}_{4,56}=15.34 ; p<0.0001\right)$ (Figure $\left.2 \mathrm{~A}\right)$, striatum $\left(\mathrm{F}_{4,54}=21.30\right.$; $p<0.0001$ ) (Figure 2B), and hippocampus $\left(\mathrm{F}_{4,51}=3.88 ; p=0.0080\right)$ (Figure 2D). Moreover, we observed GFAP upregulation in the thalamus (Figure 2C) from the 4th day and 2nd week after TBI when comparing with that in sham animals, according to Bonferroni's post hoc analysis.

We observed a significant increase in $I B A-1$ (a marker of microglia/macrophages) mRNA levels in all analyzed brain structures (cortex, striatum, thalamus, and hippocampus). The upregulation was observed in all analyzed brain areas on the 4th day after injury, except the thalamus where the mRNA increase was observed $24 \mathrm{~h}$ after TBI. The peak was observed on days 4-7 in the analyzed brain areas, and the level remained elevated in all cases at least to 7 days after brain injury compared to the level in sham-operated animals (Figure 2E-H). In the thalamus, the upregulation was maintained until 5 weeks after injury (Figure 2G). For mRNA expression of $I B A-1$, two-way ANOVA confirmed a significant interaction between the considered time points and TBI for the cortex $\left(\mathrm{F}_{4,56}=13.64\right.$; $p<0.0001$ ) (Figure 2E), striatum $\left(\mathrm{F}_{4,56}=14.77 ; p<0.0001\right)$ (Figure $\left.2 \mathrm{~F}\right)$, thalamus $\left(\mathrm{F}_{4,56}=2.90\right.$; $p=0.0299)$ (Figure $2 \mathrm{G}$ ), and hippocampus $\left(\mathrm{F}_{4,54=5.97 ;} ;=0.0005\right)$ (Figure $2 \mathrm{H}$ ). 

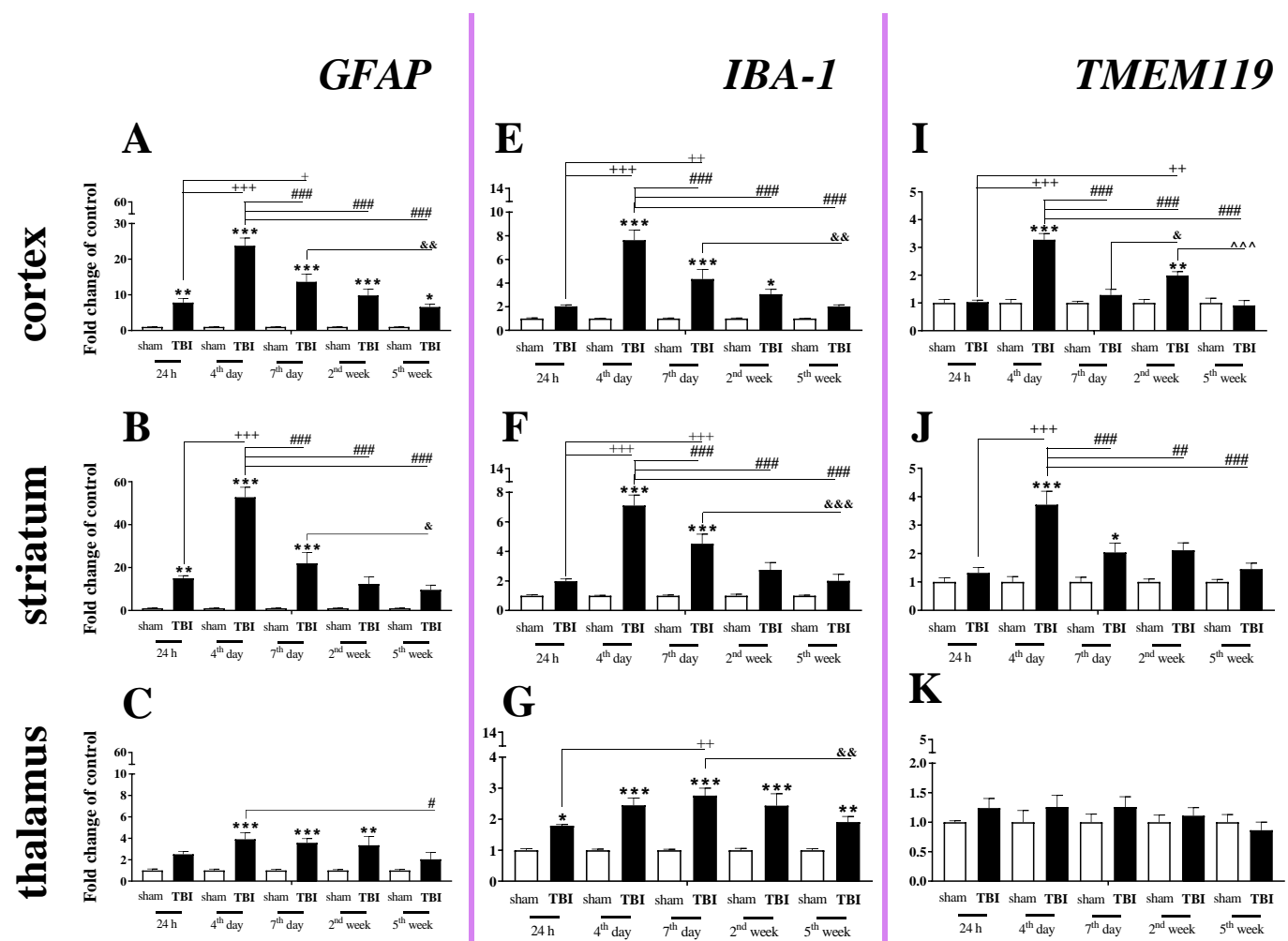

$\mathbf{K}$
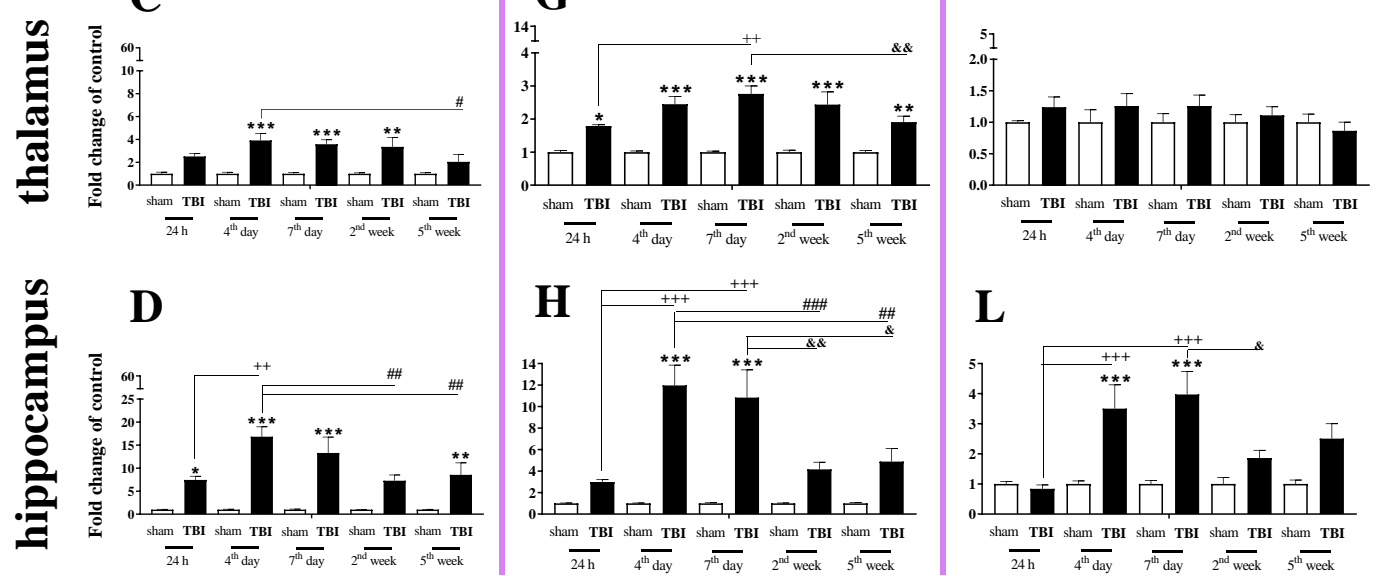

Figure 2. (A-L). The mRNA expression changes of GFAP, IBA-1, and TMEM119 in the cortex, striatum, thalamus, and hippocampus of TBI compared to sham-injured animals at different time points ( $24 \mathrm{~h}-5$ weeks). The data are given as fold changes relative to the control as mean \pm SEM (sham groups, $n=4-8$; TBI groups, $n=5-8$ ). ${ }^{*} p<0.05$; ${ }^{* *} p<0.01 ;{ }^{* * *} p<0.001$ show differences considered statistically significant between the sham and TBI groups, $+p<0.05$; $++p<0.01 ;+++p<0.001$ show differences considered statistically significant comparing to the $24 \mathrm{~h}$ TBI group; \# $p<0.05 ;$ $\# \#<<0.01$; \#\#\# $p<0.001$ show differences considered statistically significant comparing to the 4th day TBI group; \& $p<0.05$; $\& \& p<0.01 ; \& \& \& p<0.001$ show differences considered statistically significant when comparing to the 7th day TBI group; ${ }^{\wedge} p<0.001$ shows differences considered statistically significant comparing to the 2 weeks TBI group as estimated by two-way ANOVA followed by Bonferroni's post hoc test.

Elevated mRNA expression of TMEM119 (a marker of microglia) was observed in the cortex, striatum, and hippocampus (Figure 2I,J,L). In the cortex and striatum, the upregulation was first observed and it reached the highest level on the 4th day after injury (Figure 2I,J). In the hippocampus, mRNA upregulation also began 4 days after brain injury but reached a peak 4-7 days after injury, after which it decreased (Figure 2L). For mRNA expression of TMEM119, two-way ANOVA confirmed a significant interaction between the considered time points and TBI in the cortex $\left(\mathrm{F}_{4,56}=20.89 ; p<0.0001\right)$ (Figure 2I), striatum $\left(\mathrm{F}_{4,55}=6.84 ; p=0.0002\right)$ (Figure $\left.2 \mathrm{~J}\right)$, and hippocampus $\left(\mathrm{F}_{4,53}=4.51 ; p=0.0033\right)$ (Figure 2L). 
2.3. Study of GFAP and IBA-1 Protein Levels in the Cortex, Striatum, Thalamus, and Hippocampus of TBI or Sham-Injured Mice at Selected Time Points

The GFAP protein level was increased in all tested brain regions 7 days after TBI (Figure 3A-D). For GFAP protein expression, two-way ANOVA confirmed a significant interaction between the considered time points and TBI in the cortex $\left(\mathrm{F}_{1,16}=15.13 ; p=0.0013\right)$ (Figure $3 \mathrm{~A})$, striatum $\left(\mathrm{F}_{1,19}=29.64 ; p<0.0001\right)$ (Figure $\left.3 \mathrm{~B}\right)$, and hippocampus $\left(\mathrm{F}_{1,20}=11.65\right.$; $p=0.0028$ ) (Figure 3D). Moreover, we observed elevated levels of GFAP in the thalamus (Figure 3C) $24 \mathrm{~h}$ and 7 days after TBI when comparing to the levels in sham animals, according to Bonferroni's post hoc analysis. The upregulation of GFAP protein was significantly higher on the 7th day after injury when compared to its level $24 \mathrm{~h}$ after injury in all subjected brain areas, as evaluated by Bonferroni's post hoc test.

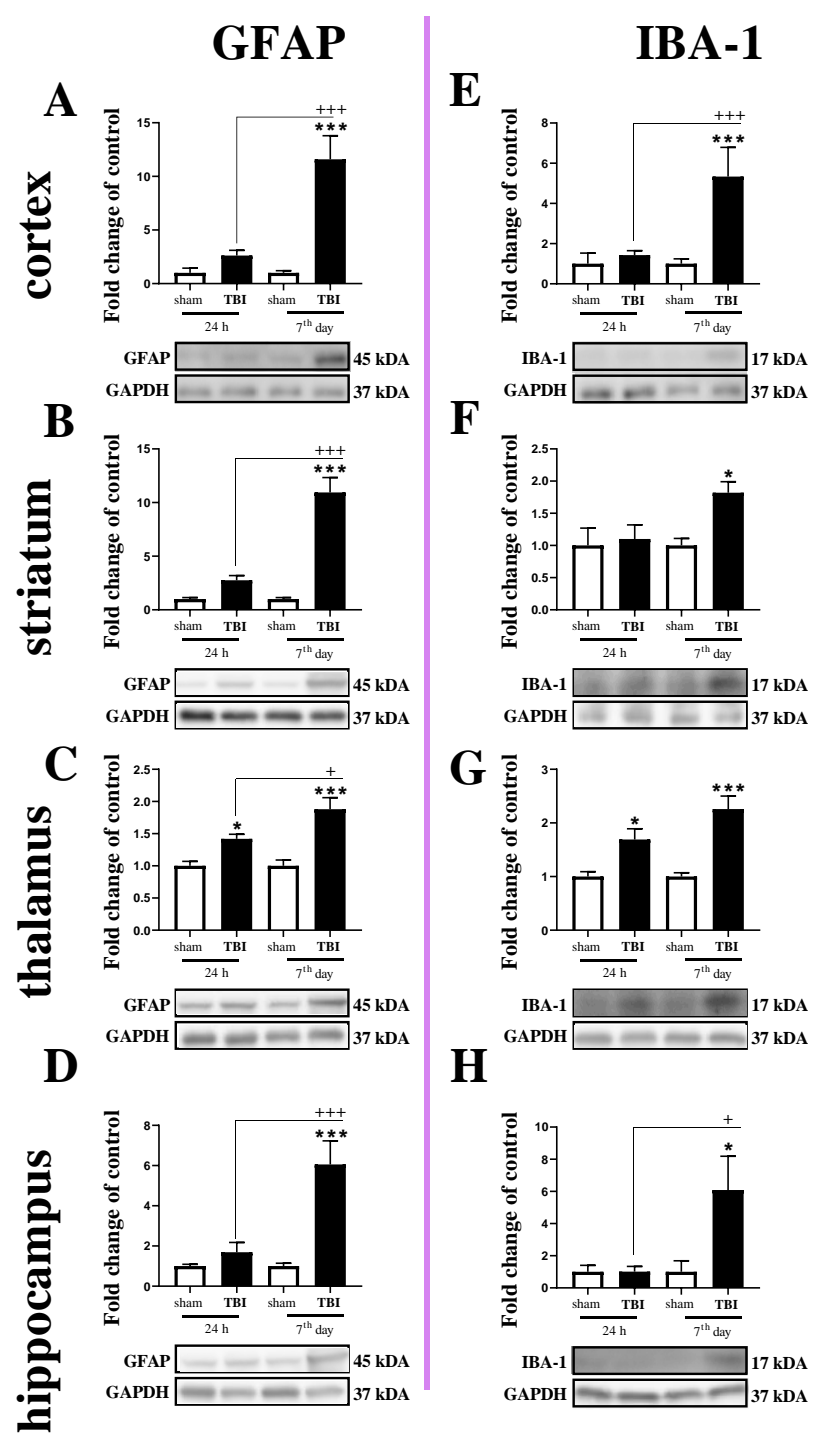

Figure 3. (A-H). The protein expression changes of IBA-1 and GFAP in the cortex, striatum, thalamus, and hippocampus of TBI compared to sham-injured animals at different time points $(24 \mathrm{~h}$ and $7 \mathrm{th}$ days). The data are given as fold changes relative to the control as mean \pm SEM (sham groups, $n=4-6$; TBI groups, $n=4-6)$. ${ }^{*} p<0.05 ;{ }^{* * *} p<0.001$ show differences considered statistically significant between the sham and TBI groups, $+p<0.05 ;+++p<0.001$ show differences considered statistically significant comparing to the $24 \mathrm{~h}$ TBI group as estimated by two-way ANOVA followed by Bonferroni's post hoc test. 
Similar to the GFAP, IBA-1 protein levels were elevated in all tested structures 7 days after TBI (Figure 3E-H). Moreover, upregulation of IBA-1 was observed in the thalamus $24 \mathrm{~h}$ after injury (Figure 3G). For IBA-1 protein expression, two-way ANOVA confirmed a significant interaction between the considered time points and TBI in the cortex $\left(\mathrm{F}_{1,14}=10.30\right.$; $p=0.0063$ ) (Figure $3 \mathrm{E}$ ) and hippocampus $\left(\mathrm{F}_{1,19}=4.56 ; p=0.0459\right)$ (Figure $\left.3 \mathrm{H}\right)$. Moreover, we observed elevated levels of IBA-1 in the striatum on the 7th day (Figure 3F) and thalamus (Figure 3G) $24 \mathrm{~h}$ and 7 days after injury when comparing with the levels in sham animals, according to Bonferroni's post hoc analysis.

\subsection{Time-Dependent Study of C1q, C1s, and C1r mRNA Expression in the Cortex, Striatum, Thalamus, and Hippocampus After TBI in Mice}

We observed a significant $C 1 q$ mRNA increase in the cortex, striatum, and thalamus from 4 days to 2 weeks following injury and in the hippocampus from 4 to 7 days following injury. The highest level was observed on the 4th day in the cortex and striatum, on week 2nd in the thalamus and on days 4-7 in the hippocampus when comparing to sham-operated animals (Figure $4 \mathrm{~A}-\mathrm{D}$ ). For $\mathrm{C} 1 q$ mRNA expression, two-way ANOVA confirmed a significant interaction between the considered time points and TBI in the $\operatorname{cortex}\left(\mathrm{F}_{4,55}=19.57 ; p<0.0001\right)($ Figure $4 \mathrm{~A})$, striatum $\left(\mathrm{F}_{4,56}=11.81 ; p<0.0001\right)$ (Figure $\left.4 \mathrm{~B}\right)$, thalamus $\left(\mathrm{F}_{4,55}=3.74 ; p=0.0092\right)$ (Figure $\left.4 \mathrm{C}\right)$, and hippocampus $\left(\mathrm{F}_{4,56}=3.67 ; p=0.0101\right)$ (Figure 4D).

Elevated C1s mRNA expression was observed in the cortex, striatum, thalamus and hippocampus. In the cortex, the upregulation began $24 \mathrm{~h}$ after TBI and remained elevated until 5 weeks (Figure 4E). In the hippocampus, the upregulation began 7 days after TBI and also remained elevated until 5 weeks. (Figure $4 \mathrm{H}$ ). For $\mathrm{C} 1 \mathrm{~s}$ mRNA expression, two-way ANOVA confirmed a significant interaction between the considered time points and TBI in the cortex $\left(\mathrm{F}_{4,55}=2.69 ; p<0.0406\right)$ (Figure $\left.4 \mathrm{E}\right)$ and hippocampus $\left(\mathrm{F}_{4,55}=3.16 ; p=0.0206\right)$ (Figure $4 \mathrm{H}$ ). Moreover, according to Bonferroni's post hoc analysis, we observed elevated levels of C1s in the striatum (Figure 4F) and the thalamus (Figure 4G) after TBI compared with levels in sham animals. Increased $C 1 s$ levels were observed between $24 \mathrm{~h}$ and 7 days after injury in the striatum and between $24 \mathrm{~h}$ and 4 days after injury in the thalamus.

Elevated expression of $\mathrm{C} 1 \mathrm{r}$ was observed in the striatum and thalamus $24 \mathrm{~h}$ after brain injury. In the hippocampus, $\mathrm{C} 1 r$ upregulation began 7 days after TBI and remained elevated until 5 weeks (Figure $4 \mathrm{~L}$ ). The highest levels of $\mathrm{C} 1 \mathrm{r}$ upregulation were observed $24 \mathrm{~h}$ after injury in the striatum and thalamus and 7 days after injury in the hippocampus (Figure 4J-L). For C1r mRNA expression, two-way ANOVA confirmed a significant interaction between the considered time points and TBI in the striatum $\left(\mathrm{F}_{4,54}=2.94 ; p=0.0285\right)$ (Figure $4 \mathrm{~J})$, thalamus $\left(\mathrm{F}_{4,49}=3.07 ; p<0.0246\right)$ (Figure $\left.4 \mathrm{~K}\right)$, and hippocampus $\left(\mathrm{F}_{4,48}=3.18\right.$; $p<0.0214)$. Moreover, according to Bonferroni's post hoc analysis, we observed elevated levels of $\mathrm{C} 1 r$ in the cortex (Figure 4I) 24 h, 4 days, and 2 weeks after TBI when compared with levels in sham animals. 

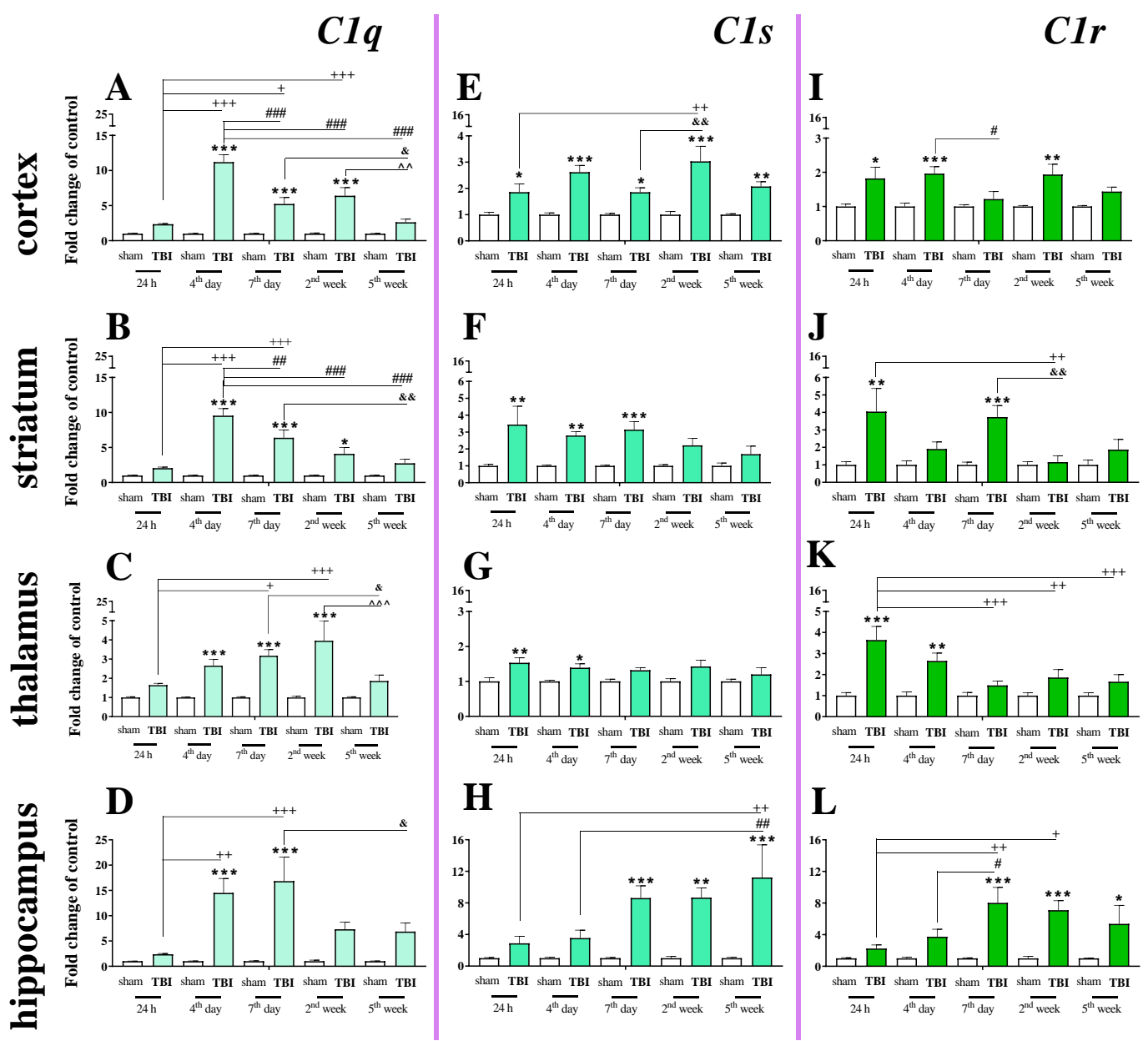

Figure 4. (A-L). The mRNA expression changes of $C 1 q, C 1 s$, and $C 1 r$ in the cortex, striatum, thalamus, and hippocampus of TBI compared to sham-injured animals at different time points ( $24 \mathrm{~h}-5$ weeks). The data are given as fold changes relative to the control as mean \pm SEM (sham groups, $n=3-8$; TBI groups, $n=4-8$ ). ${ }^{*} p<0.05 ;{ }^{* *} p<0.01 ;{ }^{* * *} p<0.001$ show differences considered statistically significant between the sham and TBI groups, $+p<0.05 ;++p<0.01 ;+++p<0.001$ show differences considered statistically significant comparing to the $24 \mathrm{~h}$ TBI group; $p<0.05$; \#\# $p<0.01$; \#\#\# $p<0.001$ show differences considered statistically significant comparing to the 4th day TBI group; \& $p<0.05$; \&\& $p<0.01$ show differences considered statistically significant when comparing to the 7th day TBI group; ${ }^{\wedge} p<0.01 ;{ }^{\wedge} p<0.001$ show differences considered statistically significant comparing to the 2 weeks TBI group as estimated by two-way ANOVA followed by Bonferroni's post hoc test.

\subsection{C1q Localization in the Contused Tissue}

Immunofluorescence analysis confirmed the presence of $\mathrm{C} 1 \mathrm{q}$ in the contused cortex $96 \mathrm{~h}$ after TBI. Interestingly, C1q localizes to brain vessels and cell-like structures (Figure 5A). 

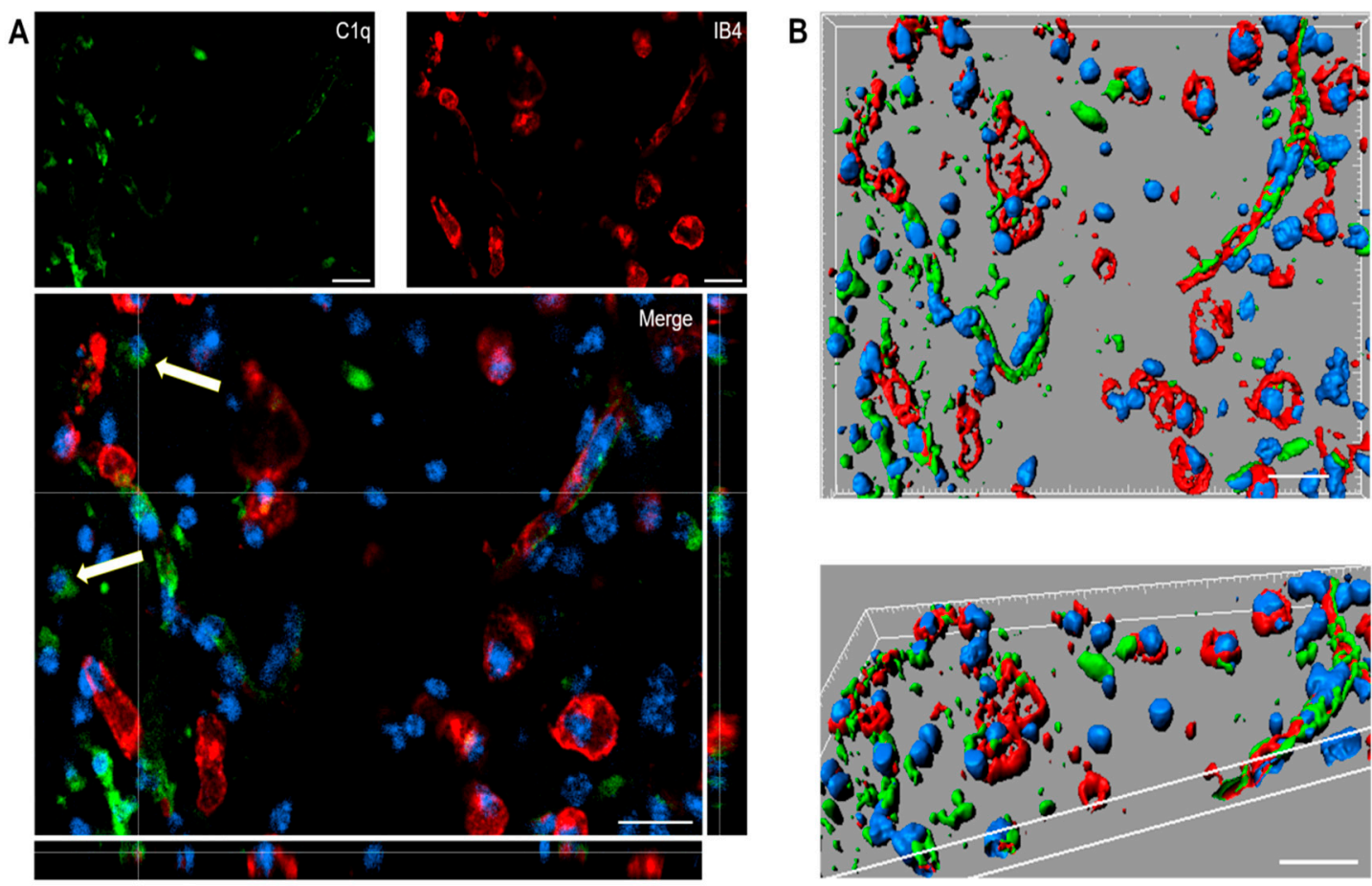

Figure 5. (A,B). Confocal analysis of C1q localization in the contused cortex $96 \mathrm{~h}$ after TBI. (A) C1q (green) is present on brain vessels (IB4, red) and in cell-like structures (arrows). Nuclei are in blue. (B) Three-dimensional image rendering shows $\mathrm{C} 1 \mathrm{q}$ in vessels. Images are representative of at least two independent experiments. Scale bar $=20 \mu \mathrm{m}$.

Confocal analysis was performed of $\mathrm{C} 1 \mathrm{q}$ and microglia/macrophage localization in the contused cortex $96 \mathrm{~h}$ after TBI (Figure 6). Panels A and D show that C1q does not generally colocalize with microglia/macrophages, although it localizes in close proximity to them. Instead, C1q appears with vessel-like morphology, as shown in Figure 5. Panels B and $C$ show the high magnification, three-dimensional image rendering of $C 1 q$ inside $\mathrm{Cd} 45$ positive cells. Panels E and F show the high magnification, three-dimensional image rendering of $\mathrm{C} 1 \mathrm{q}$ surrounded by microglia/macrophages. Images are representative of at least two independent experiments. 


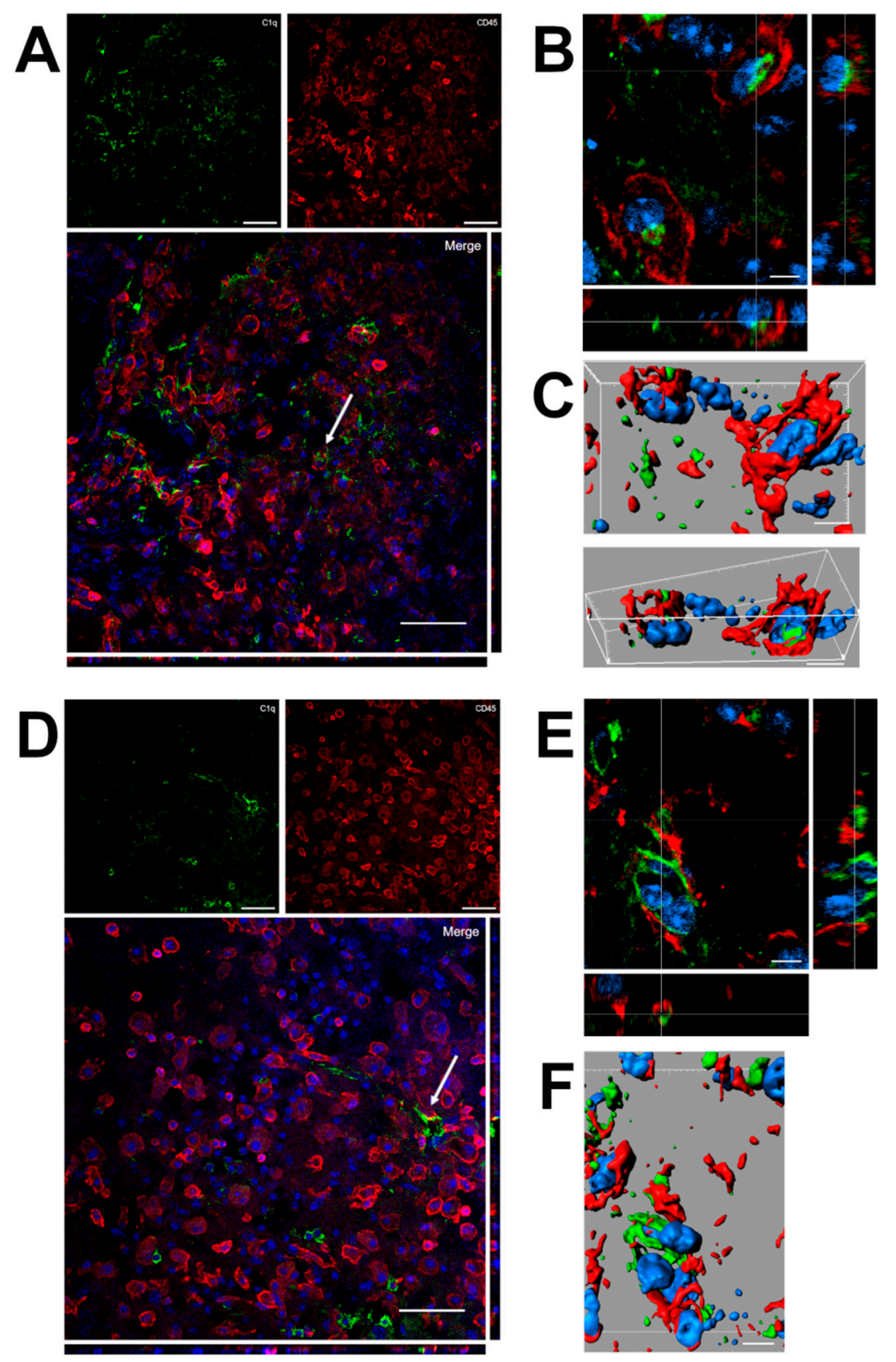

Figure 6. (A-F). Confocal analysis of $\mathrm{C} 1 \mathrm{q}$ and microglia/macrophage reciprocal localization in the contused cortex $96 \mathrm{~h}$ after TBI. (A,D) C1q (green) does not generally colocalize with microglia/macrophages (Cd45, red) although it appears in close proximity to them (arrow in A). C1q appears with vessels-like morphology (arrow in D), as shown in Figure 5. Scale bar $=50 \mu \mathrm{m}$. (B,C). High magnification, threedimensional image rendering shows $\mathrm{C} 1 \mathrm{q}$ localization inside $\mathrm{Cd} 45$ positive cells. (E,F) High magnification, three-dimensional image rendering shows $\mathrm{C} 1 \mathrm{q}$ surrounded by microglia/macrophages. Images are representative of at least two independent experiments. Nuclei are in blue. Scale bar $=5 \mu \mathrm{m}$.

Figure 7 shows confocal analysis of $\mathrm{C} 1 \mathrm{q}$ and astrocyte localization in the contused cortex $96 \mathrm{~h}$ after TBI. C1q is present along the border of the lesion, but it does not specifically co-localize with astrocytes. 

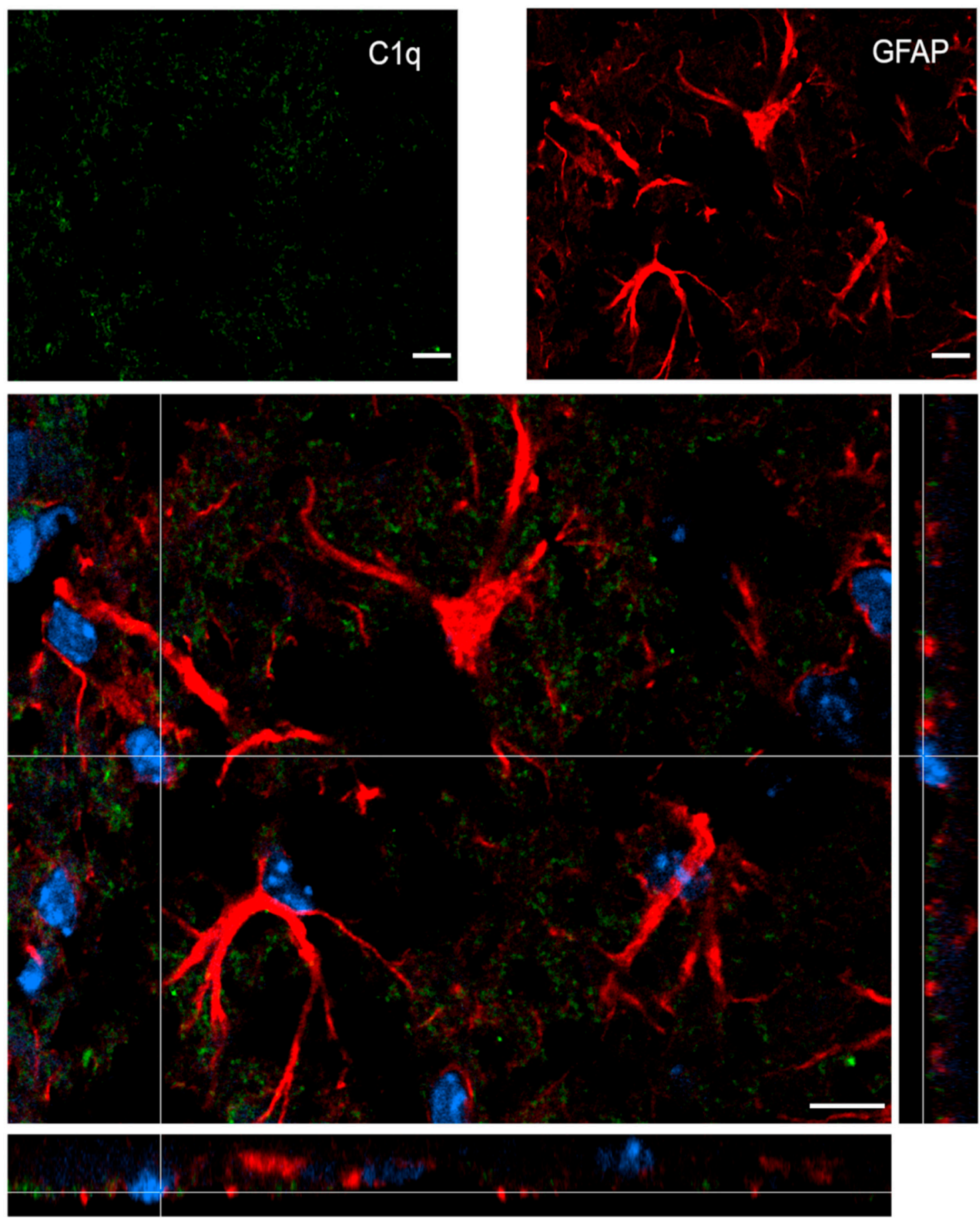

Figure 7. Confocal analysis of $\mathrm{C} 1 \mathrm{q}$ and astrocyte reciprocal localization in the contused cortex $96 \mathrm{~h}$ after TBI. A high magnification image shows that C1q (green) does not specifically colocalize with astrocytes (GFAP, red). Nuclei are in blue. Images are representative of at least two independent experiments. Scale bar $=10 \mu \mathrm{m}$.

Figure 8 shows confocal analysis of $\mathrm{C} 1 \mathrm{q}$ and neuronal localization in the contused cortex $96 \mathrm{~h}$ after TBI. 

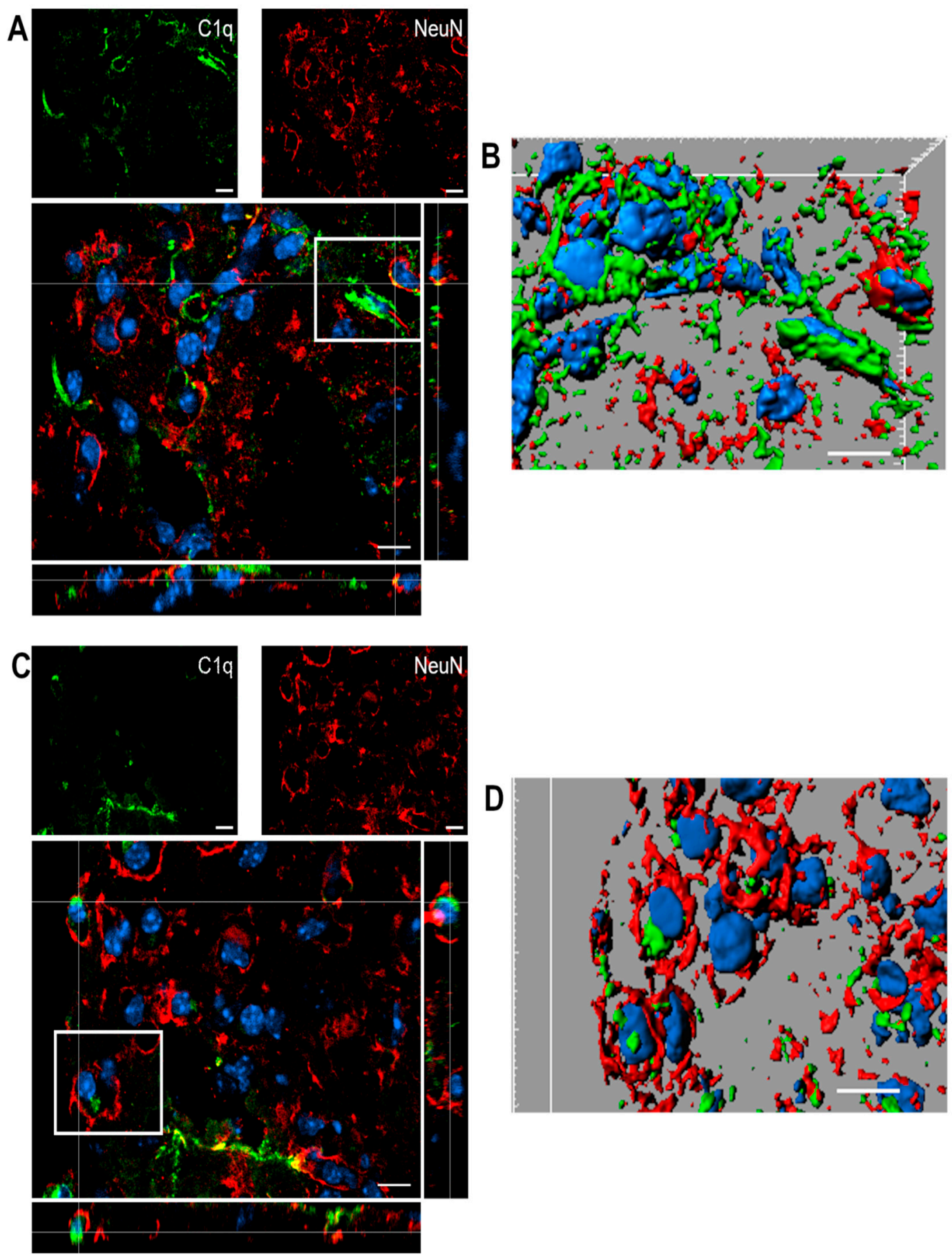

Figure 8. (A-D). Confocal analysis of C1q and neuron reciprocal localization in the contused cortex $96 \mathrm{~h}$ after TBI. (A,C) C1q (green) is present along the border of the lesion close to neurons (NeuN, red). C1q frequently localizes in close proximity to neurons. (B-D) Three-dimensional image rendering shows C1q colocalization with neurons, possibly driving apoptosis. Images are representative of at least two independent experiments. Nuclei are in blue. Scale bar $=10 \mu \mathrm{m}$.

2.6. Time-Dependent Study of Mannose Binding Lectin A and C, Collectin 11, Ficolin A and Ficolin B mRNA Expression in the Cortex, Striatum, Thalamus, and Hippocampus After TBI in Mice

Basal mRNA levels of collectin 11 (Figure 9A-D), ficolin A (Figure 9E-H) and ficolin B (Figure 9I-L) were detected in the brains of control mice, but mannose binding lectin $A$ and mannose binding lectin $C$ mRNA were not detected (Table 1). 

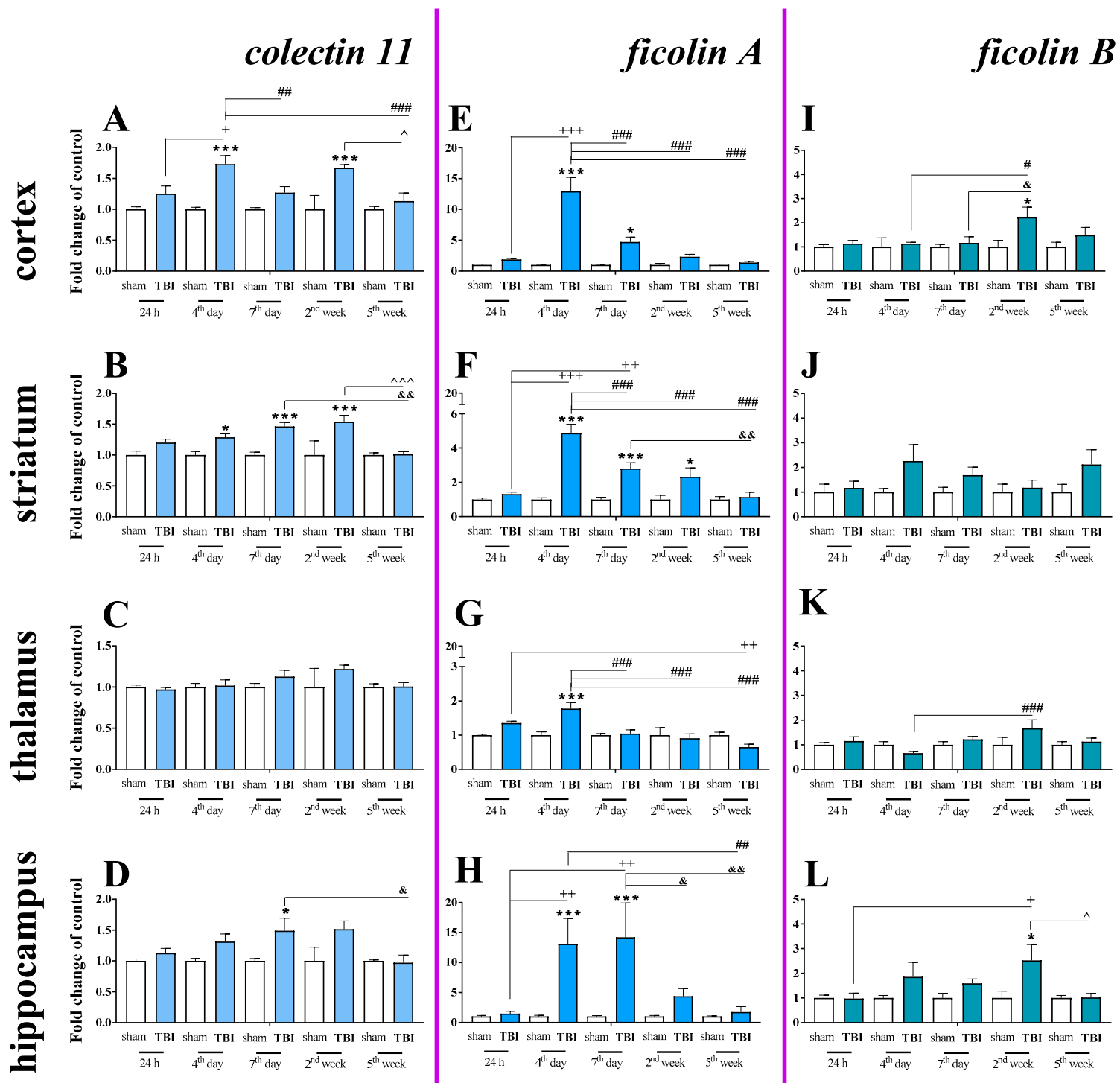

Figure 9. (A-L). The mRNA expression changes of collectin 11, ficolin A, and ficolin B in the cortex, striatum, thalamus, and hippocampus of TBI compared to sham-injured animals at different time points ( $24 \mathrm{~h}-5$ weeks). The data are given as fold changes relative to the control as mean \pm SEM (sham groups, $n=3-8$; TBI groups, $n=4-8$ ). ${ }^{*} p<0.05$; ${ }^{* * *} p<0.001$ show differences considered statistically significant between the sham and TBI groups, $+p<0.05 ;++p<0.01 ;+++p<0.001$ show differences considered statistically significant comparing to the $24 \mathrm{~h}$ TBI group; $p<0.05 ; \# \#<<0.01$; \#\#\# $p<0.001$ show differences considered statistically significant comparing to the 4 th day TBI group; $\& p<0.05 ; \& \& p<0.01$; show differences considered statistically significant when comparing to the 7th day TBI group; ${ }^{\wedge} p<0.05 ;{ }^{\wedge} \wedge p<0.001$ show differences considered statistically significant comparing to the 2 weeks TBI group as estimated by two-way ANOVA followed by Bonferroni's post hoc test.

Table 1. The mannose binding lectin $A(M B L-A)$ and mannose binding lectin $C(M B L-C)$ mRNA expression in brain structures (cortex, striatum, thalamus, and hippocampus) of sham/TBI-injured mice at selected time points ( $24 \mathrm{~h}, 4$ days, 7 days, 2 weeks, 5 weeks) was not detected.

\begin{tabular}{ccl}
\hline Brain Areas & $M B L-A$ & $M B L-C$ \\
\hline cortex & not detected & not detected \\
\hline striatum & not detected & not detected \\
\hline thalamus & not detected & not detected \\
\hline hippocampus & not detected & not detected \\
\hline
\end{tabular}


Moreover, changes in collectin 11 (Figure 9A-D), ficolin A (Figure 9E-H) and ficolin $B$ (Figure 9I-L) mRNAs were also detected after brain injury. Following TBI, elevated collectin 11 mRNA levels were observed in the cortex and striatum, beginning on 4 days after TBI and were observed until 2 weeks following injury when compared to the levels observed in the sham group (Figure 9A,B). We did not observe any changes in expression of collectin 11 in the thalamus (Figure 9C). For collectin 11 mRNA expression, two-way ANOVA confirmed a significant interaction between the considered time points and TBI in the cortex $\left(\mathrm{F}_{4,56}=3.54 ; p=0.0121\right)$ (Figure $\left.9 \mathrm{~A}\right)$ and striatum $\left(\mathrm{F}_{4,56}=3.24 ; p=0.0184\right)$ (Figure $\left.9 \mathrm{~B}\right)$. Moreover, according to Bonferroni's post hoc analysis, we observed elevated collectin 11 levels in the hippocampus (Figure 9D) on the 7th day after TBI when compared to the levels in sham animals.

After TBI, ficolin A mRNA levels were significantly increased in all analyzed brain structures (the cortex, striatum, thalamus, and hippocampus) in comparison to the levels in sham-operated animals. The upregulation was observed in all brain structures on the 4th day after TBI and also peaked on the 4th day after injury in the cortex, striatum, and thalamus (Figure 9E-G). However, the highest hippocampal ficolin A mRNA levels were observed on days 4-7 after injury (Figure 9H). For ficolin A mRNA expression, two-way ANOVA confirmed a significant interaction between the considered time points and TBI in the cortex $\left(\mathrm{F}_{4,56}=14.38 ; p<0.0001\right)$ (Figure $\left.9 \mathrm{E}\right)$, striatum $\left(\mathrm{F}_{4,56}=13.41 ; p<0.0001\right)$ (Figure $9 \mathrm{~F})$, thalamus $\left(\mathrm{F}_{4,56}=7.28 ; p<0.0001\right)$ (Figure $\left.9 \mathrm{G}\right)$, and hippocampus $\left(\mathrm{F}_{4,52}=4.04\right.$; $p=0.0063$ ) (Figure 9H).

Moreover, according to Bonferroni's post hoc analysis, we observed elevated levels of ficolin $B$ in the cortex and hippocampus after TBI (Figure 9I,K,L) when comparing to levels in sham animals.

2.7. Study of C1q, C1s, C1r, Mannose Binding Lectin A, Mannose Binding Lectin C, Collectin 11, Ficolin A, and Ficolin B mRNA Expression in Primary Microglial Cultures After LPS Treatment

The basal mRNA levels of C1q (Figure 10A), C1s (Figure 10B), and C1r (Figure 10C) were assessed in primary microglia cell cultures. After LPS stimulation, a significant increase in all the initiators of the classical pathway was observed (Figure 10A-C). In primary microglial cell cultures, after LPS stimulation, increased mRNA levels were observed for $\mathrm{C} 1 \mathrm{q}(1.74 \pm 0.14(\mathrm{t} 4=4.96 ; p=0.0077))($ Figure 10A), C1s $(6.84 \pm 1.79(\mathrm{t} 4=3.25 ; p=0.0314))$ (Figure 10B), and $C 1 r\left(7.92 \pm 1.72\left(\mathrm{t}_{4}=4.01 ; p=0.0160\right)\right)$ (Figure 10C).

Further, the basal mRNA levels of collectin 11 (Figure 10D) and ficolin $A$ (Figure 10E) but not ficolin $B$, mannose binding lectin $A$, or mannose binding lectin $C$ (Figure 10F) were assessed in primary microglial cell cultures. After LPS stimulation, a significant decrease in ficolin $A\left(0.65 \pm 0.44\left(\mathrm{t}_{4}=3.4 ; p=0.0273\right)\right)$ (Figure 10E) was observed. 


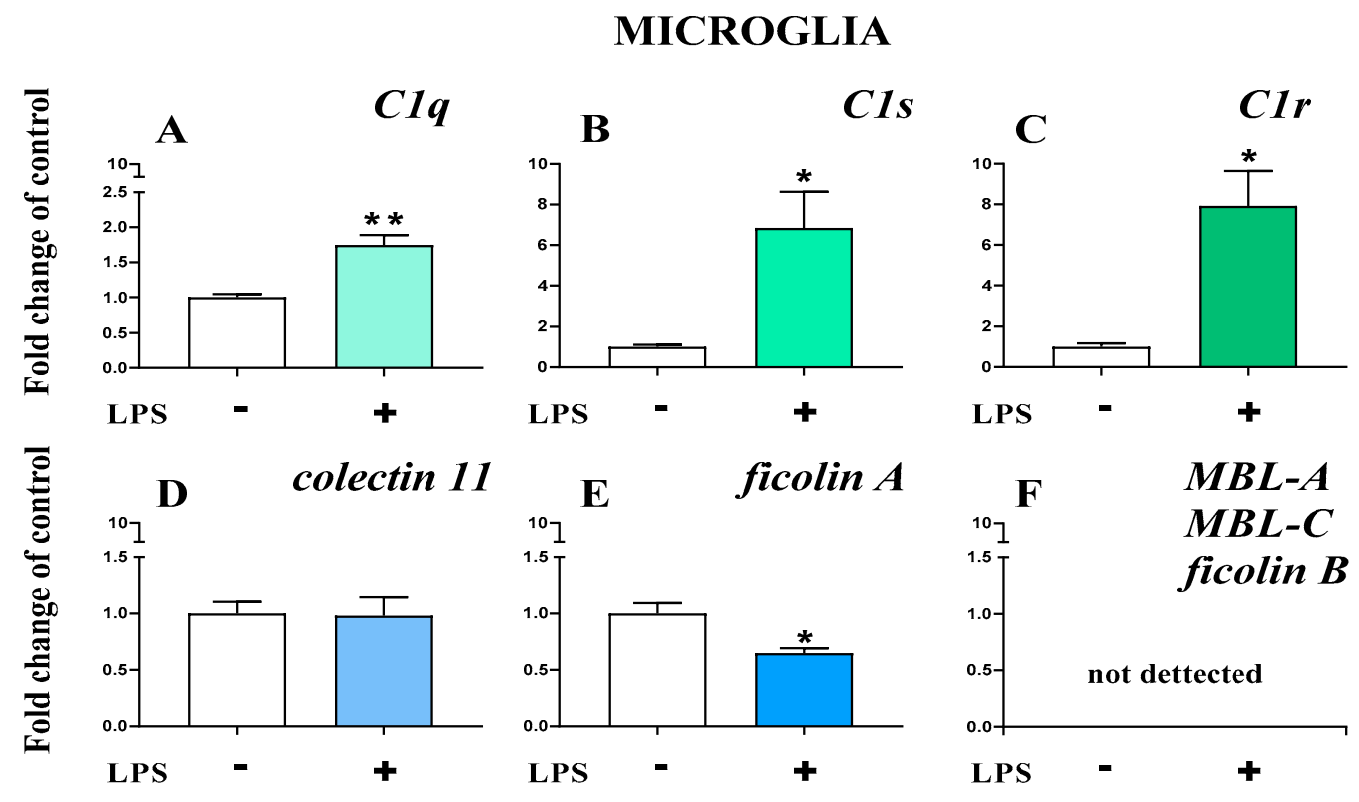

Figure 10. (A-F). The changes in initiators of classical pathway [green]: C1q, C1s, C1r; lectin pathway [blue]: mannose binding lectin $A$ and $C(M B L-A, M B L-C)$, collectin 11, ficolin $A$, and ficolin $B$ mRNA expression in primary microglial cultures. The data are the mean $\pm \operatorname{SEM}(n=3) .{ }^{*} p<0.05 ;{ }^{* *} p<0.01$ indicate significant differences between non-stimulated (-) and LPS-stimulated (+) cultures.

\section{Discussion}

The contribution of the complement system to acute brain injury is well known. While it is widely recognized that circulating complement cascade components enter the brain through a damaged blood-brain barrier, the possibility that the brain itself may respond to injury with a local synthesis of complement components has been scarcely explored. Herein, we have documented the ipsilateral spatiotemporal activation and mRNA expression of initiators of the classical (C1q, C1s, C1r) and lectin (collectin-11, ficolin A, ficolin $B$ ) complement pathways in murine brain structures after TBI. Importantly, our study has revealed, for the first time, that these complement changes are detected not only in the cortex but also in other brain regions, such as the striatum, hippocampus, and thalamus. In parallel, we have detected significant changes in the mRNA levels of a wide spectrum of cellular markers for neutrophils, $\mathrm{Cd} 8+\mathrm{T}$ cells, astroglia, and microglia/macrophages. Our data added to the knowledge that C1q, C1s and C1r (the C1q complex), and ficolin A are important factors in the brain, and we assert that the roles of these proteins should be fully elucidated.

Interestingly, $\mathrm{C} 1 \mathrm{q}$ and its complex components are detected in strongly activated microglial cells. Moreover, our in vitro experiments using primary cells cultures confirmed that microglial cells can synthesize classical pathway initiators but are unlikely to be responsible for elevated levels of lectin pathway initiators. Therefore, strategies that modulate microglial activation and/or blockade of the C1q complex may represent a promising opportunity for effective therapies in brain damage. It has been previously shown that C1-inhibitor protects from focal brain trauma in mice by reducing thrombo inflammation and diminishing upregulation of proinflammatory factors, such as CCL2, CCL3, IL-beta, and tumor Necrosis Factor alpha (TNF- $\alpha$ ) [15]. Previous studies also show that administration of C1-inhibitor shortly after TBI, attenuates cognitive deficits and histological damage [16]. Moreover, it was reported that C1-inhibitor attenuates neurobehavioral deficits and reduces contusion volume after TBI in mice [17]. Therefore, the role of the C1q complex requires in-depth pharmacological investigation.

Brain injury is known to evoke an inflammatory reaction that involves several interrelated mechanisms, including release of intracellular components from damaged cells to the 
parenchyma, production of complement factors and cytokines, activation of brain-resident cells, and recruitment of peripheral immune cells into the brain $[18,19]$. Many of these processes influence each other, leading to complex interactions. Over the last years, because of heterogeneous changes observed in patients with TBI, different animal models have been developed with the aim of reproducing a complex clinical condition and to obtain tools to better recognize the underlying pathophysiology [20]. Among them, 3 models are widely used in particular: CCI [13,21,22], fluid percussion injury (FPI) [23] and impact acceleration model of diffuse traumatic brain injury (DTBI) [24]. CCI is a dynamic direct impact injury which replicates clinical brain injury with skull deformation and related cortical compression. It offers a very good control of injury parameters such as velocity of impact, depth, and angle, resulting in a highly reproducible impact $[13,21,22]$, a potential advantage over other models such as FPI. A few changes measured in our study using CCI are similar to those observed by others in FPI model, for example after one week both injuries show enhanced cortical and/or hippocampal infiltration and/or activation of GFAP+, IBA-1+, and TMEM+ cells [7,25-27]. Importantly, CCI reproduces changes reported in clinical head injuries and documented in several studies such as: concussion, contusion, hemorrhage, traumatic axonal injury and cortical inflammatory changes, brain edema, elevated intracerebral pressure, reduced cortical perfusion, decreased cerebral blood flow, neuroendocrine, and both inflammatory and metabolic changes [10,20,28,29]. Therefore, learning about neuroimmune interactions from animal models of TBI may foster the development of future therapies. Knowledge about the brain regions affected by the cascade of events triggered by TBI is limited; therefore, we decided to expand our studies to other brain areas. The results demonstrated that cellular changes in CCI occurred not only in the cortex (which was the injury site corresponding to the most expected changes) but also in the striatum, hippocampus, and thalamus. We showed the spatiotemporal mRNA expression of cellular markers and complement initiators in different brain areas (cortex, striatum, thalamus, and hippocampus), which were previously suggested to be especially susceptible in TBI [30-32]. It was previously demonstrated in a closed head diffuse injury rat model that TBI leads to wide, long-lasting microstructural alterations in white and gray matter [33]. Moreover, the same brain areas we studied (cortex, striatum, thalamus, and hippocampus) appeared to be especially susceptible to ongoing post-TBI pathology in previous studies, which was confirmed by volumetric changes in these areas and/or significantly higher activation of microglia/macrophages when compared to the sham group (up to 30 days) [33]. Additionally, after TBI, positron emission tomography confirmed an increased level of inflammation in the thalamus [10].

One of the most important first-line players at the sites of injury are neutrophils [34]. Our results showed that the mRNA level of $C d 177$ (a marker of neutrophils) is upregulated and peaks on the 4th day after brain damage in the cortex and also in the striatum and hippocampus to a lesser extent. This observation is in agreement with previous studies, which show that recruitment of neutrophils into the injured cortex occurs over a period of approximately 3 days [6]. In early stages of injury, activated neutrophils bind to the endothelium and platelets and as a consequence, hinder the blood flow through vessels [35]. Moreover, as a source of several inflammatory mediators, such as proinflammatory cytokines, reactive oxygen species (ROS) and matrix metalloproteinases (MMPs), neutrophils contribute to the development of severe complications after TBI [36,37]. Conversely, some studies have shown that neutrophils also affect nerve repair by releasing transforming growth factor $\beta$ (TGF- $\beta$ ), nerve growth factor (NGF), IL-4, and IL-10 [6], and that is why the role of those cells is rather dualistic. Neutrophils are regarded as important short-lived players in brain injury, in contrast to Cd8+T cells [38-40]. After TBI in mice, an increase in Cd8+ T cells can be observed in the cortex up to 8 weeks after injury [41]. Additionally, it has been shown, in experimental stroke, that mice display improved behavioral function and decreased neuronal loss following the depletion of Cd8+T cells [42]. Our data confirm the presence of $\mathrm{Cd} 8+\mathrm{T}$ cells in the cortex both during early and later phases; however, the maximal activation levels are reached at later time points. Importantly, 
our results give evidence that the observed changes are not limited to the cortex but are also present in the striatum, thalamus, and hippocampus. Based on the literature [41], one may believe that after TBI, Cd8+ T cells promote secondary neuronal and myelin degeneration not only in the cortex but also in other brain regions. Oligodendrocytes are required for producing and maintaining myelin throughout the brain. Our data show that after TBI, Olig2+, which is a marker of immature oligodendrocytes, is only briefly and slightly upregulated in the cortex, striatum, and hippocampus after injury, which is in agreement with others [43]. After TBI, decreased activity of CC-1+, which is a marker of mature oligodendrocytes, has been reported in the literature [43], and this is in line with our results showing that new immature oligodendrocytes do not form after TBI, which contributes to the gradual degeneration of myelin. In contrast, TBI has been shown to evoke the activation of astrocytes, the most abundant cell type in the brain $[44,45]$. This is in agreement with our results showing the increased expression of GFAP, the astroglial activation marker, in the cortex, striatum, thalamus, and hippocampus. Therefore, the serum GFAP level appears to be a good prognostic marker of TBI [46]. The literature shows that astrocytes can have some protective functions in the injured brain, e.g., through the release of neurotrophic factors $[47,48]$. Homeostatic astrocytes are critical for maintaining normal function of the blood-brain barrier [49]; however, the major result of astrocyte activation is the formation of glial scars, which function as a barrier to axonal regeneration and extension [47,50]. Herein, we observed significant GFAP level changes in the brain starting early after injury and lasting up to 5 weeks. In a very recent study, it was shown that monitoring IBA-1 in serum might provide clinically relevant insights into the underlying TBI pathophysiology [51]. The IBA-1 is a monocytes/microglia/macrophagesspecific calcium-binding protein that participates in membrane ruffling and phagocytosis of those cells. Among IBA-1 positive cells, activated monocytes infiltrate into the brain after injury and propagate breakdown of the BBB by secreting a variety of inflammatory mediators. Recently Ly6 $C^{\text {lo }}$ non-classical monocytes were suggested to be necessary for the recruitment of neutrophils [52], while CD115 ${ }^{+} \mathrm{Ly}_{6 \mathrm{C}}{ }^{-\mathrm{hi}} \mathrm{CD} 62^{+} \mathrm{CCR} 2{ }^{\text {hi }}$ classical monocytes, infiltrate into the injured brain, and become tissue macrophages [53]. Macrophages and microglia are considered to be important players in maintaining brain homeostasis in the response to injury [54,55]. Long-term increased IBA-1 levels after brain injury indicate that those cells become activated and/or infiltrate to injured regions, both in early and late phases [56]. These processes may lead to neuroinflammation, which may have some protective functions but also may cause secondary brain injury and neurodegeneration $[56,57]$. Our current study indicates that the upregulated mRNA and protein levels of IBA-1 reflect long-term activation in the cortex and other brain regions, such as the striatum, hippocampus, and thalamus. The role of microglia in TBI may also be confirmed by the presence of transmembrane protein 119 (TMEM119), which is exclusively expressed on those cells [58-60]. Our data has revealed for the first time that following TBI, TMEM119 is upregulated for up to 2 weeks in the cortex, what may be connected with loss of microglia homeostatic functions. Therefore, future studies are required to determine the exact role of microglia during TBI, including the role in complement activation. It has already been shown that C1q can be produced by microglia cells [61,62]; however, our data provide evidence that microglia are also a source of $C 1$ s and $C 1$. In sum, our results suggest that microglia possess the machinery for production of the C1q complex, which can be triggered after their activation. Whether or not this is related to activation of the complement cascade or if $\mathrm{C} 1 \mathrm{q}$ possess independent actions is still to be clarified. This may be similar to what was recently shown for MBL, which can exert a direct deleterious effect on ischemic brain endothelial cells independently from complement activation [63].

$\mathrm{C} 1 \mathrm{q}$ is a recognition and initiator molecule of the classical complement activation pathway, which binds to targets (immune complexes), leading to serine protease C1r activation, which cleaves and activated $\mathrm{C} 1 \mathrm{~s}$ - its substrate. $\mathrm{C} 1 \mathrm{q}$ is synthesized by brain macrophages and microglia $[12,64,65]$ and is involved in the initiation of those cells activation in the extrinsic plasma, during the occurrence of central nervous system (CNS) 
diseases characterized by BBB impairment [12]. Moreover, C1q is synthesized by activated microglia/macrophages and because of that, it is considered to be the marker of their activation [66], which is in agreement with the results of our IHC and in vitro analysis. A previous in vitro study has shown that $\mathrm{C} 1 \mathrm{q}$ evokes calcium signaling in microglia/macrophages and triggers the release of cytokines [12]. Therefore, it appears that this defense protein complex is likely to contribute, in an autocrine/paracrine way, to microglia/macrophages homeostasis. Under physiological conditions, the level of C1q is low in the CNS, but it increases significantly after damage or during infections, which is evident in animal model studies of blood-brain barrier dysfunction [64], transient global cerebral ischemia [65], virus infections [67], and spinal cord injury [68]. Importantly, C1q upregulation has been reported in humans during neurodegenerative impairments, such as Alzheimer's disease, frontal temporal dementia, West Nile Virus infection, and schizophrenia [69-72]. Additionally, studies in C1q-deficient mice reveal that $\mathrm{C} 1 \mathrm{q}$ has a detrimental effect on the development of CNS diseases, such as Alzheimer's [73] and prion [74] diseases. Further, it has been shown that $\mathrm{C} 1 \mathrm{q}$ deficiency improves histological and functional locomotor outcomes after spinal cord injury [75]; however, motor function recovery has not been observed after brain injury [76]. It has been shown that accumulation of C1q on synapses within the hippocampus occur in parallel with synapse loss 30 days post TBI [77]. It was also demonstrated that $\mathrm{C} 1 \mathrm{q}$-dependent complement activation contributes to hypoxic-ischemic brain injury in mice, and deletion of the $C 1 q$ gene confers significant and long-lasting neuroprotection [78]. However, C1q is not only the classical complement pathway initiator, but it has also been implicated in several functions that may be independent of the complement cascade, including the regulation of synaptic pruning, protection against neurotoxicity, and promotion of angiogenesis [79]. In the TBI model, we also observed a significant upregulation in C1q mRNA with major changes on days 4-7 and 2 weeks in the thalamus, and this enhancement was maintained up to 2 weeks after injury in all studied brain regions (except the hippocampus). Importantly, these changes occurred in parallel with the $I B A-1$ mRNA upregulation, suggesting that microglia/macrophages are the source of C1q. This is confirmed by IHC results, showing the co-localization of C1q and Cd45. In 2017, Thielens et al. proposed that the role of C1q in the brain may not be related only to activation of the classical pathway [80]. There are different ways by which $\mathrm{C} 1 \mathrm{q}$ can bind to the receptors and target the cells: by the collagen-like tail (cC1qR) and the globular head of the molecule (gC1qR), also by different ligands like heparan sulfate $[80,81]$. Therefore, $\mathrm{C} 1 \mathrm{q}$ has also been reported to induce expression of adhesion molecules [82], enhance the release of proinflammatory cytokines [83], recognize apoptotic endothelial cells [84], and stimulate expression of genes in neurons that are associated with neuroprotection [85]. Interestingly, an in vitro study showed that C1q suppresses the LPS-evoked production of proinflammatory factors TNF- $\alpha$, IL- $1 \beta$, and IL-6, suggesting its homoeostatic and anti-inflammatory role in the CNS [86]. Importantly, in vitro studies show that $\mathrm{C} 1 \mathrm{q}$, in the absence of $\mathrm{C} 1 \mathrm{r}$ and $\mathrm{C} 1 \mathrm{~s}$, induces gene expression that is critical for neuronal survival and neurite outgrowth [85,87] and protects against oligomeric and fibrillar A $\beta$-induced (amyloid beta induced) neuronal death [79]. However, after TBI, the mRNA levels of $C 1 q, C 1 r$, and $C 1 s$ increase, which may be one of the reasons for secondary injury development after TBI. Moreover, these changes are not only observed in the cortex but are also observed in other brain regions, such as the striatum, hippocampus, and thalamus, and may contribute to the progression of neurodegeneration. Our results are in line with those obtained in FPI model in injured cortex and hippocampus [88]. In addition, our study provides the first evidence that strong changes appear in striatum, a structure involved in movement planning, as well as in cognition and reward processes and in the thalamus, an area important for consciousness, arousal, cognition, behavior, working memory, executive function, motor control, sustained, and vigilant attention [89]. Noticeable changes are also detected in the hippocampus, the brain region responsible for cognition, memory deficits, and epileptic seizures associated with TBI [31]. Thus, our data demonstrate that in these important areas of the brain, there is a strong activation of the 
initiators of the classical complement activation pathway, paving the way to the development of novel effective pharmaceutical agents. It appears that $\mathrm{C} 1 \mathrm{q}$ is neuroprotective only when acting independently (without $\mathrm{C} 1 \mathrm{r}$ and $\mathrm{C} 1 \mathrm{~s}$ ); however, during $\mathrm{TBI}$, the entire $\mathrm{C} 1 \mathrm{q}$ complex appears to be involved. Recently, the $\mathrm{C} 1$-inhibitor has been proposed as an attractive candidate for treatment of neurological disorders associated with inflammation [15], including stroke [90] and TBI [17]. In our opinion, because there are many diseases wherein C1q-complex targeting may be successful, further studies addressing the downstream consequences of activation of this multifunctional complex will be critical to develop therapy for TBI and other neuroinflammation-related diseases.

While the C1q-complex components may be synthesized in the brain, MBL is mainly produced by liver and is the typical source of complement proteins [91,92]. Our results give evidence for a lack of $M B L-A$ and $M B L-C$ mRNA in all studied brain structures, even after TBI. Further, our in vitro experiments confirm the lack of MBLs biosynthesis by primary microglia, even after their activation. However, it is conceivable that MBL can enter the brain from the blood through the injured blood-brain barrier and may act as a chemoattractant for immune cells [93]. Although MBL is not synthesized in the brain, it plays an important role after brain injury. Notably, MBL knockout mice or mice receiving an MBL inhibitor show attenuated motor deficits and reduced neuronal cell loss following injury [94]. Unlike MBL, collectin-11 shows cerebral synthesis and its mRNA expression is activated by TBI. It has been previously shown that expression of collectin 11 rapidly increases in the post-ischemic period and colocalizes with complement proteins deposited along the basolateral surface of the proximal renal tubule [95]. Our experimental results show, for the first time, that there is slight upregulation of collectin-11 mRNA in the mouse cortex, hippocampus, and striatum after TBI. Moreover, since there is no upregulation of collectin-11 mRNA in primary microglia after their activation, those cells may not be the main source of collectin- 11 in the brain. Moreover, it has been recently reported that collectin-11 knock-out mice do not show an improved sensorimotor response compared to wild type mice [96], which suggests that this initiator of the lectin pathway is not crucial in TBI.

We have previously demonstrated that ficolin-1, -2 , and -3 are present in the contused human brain; however, their role remains unclear. Therefore, ficolins were investigated in the murine model herein. In humans, ficolin- 1 can be detected close to vasculature and in brain parenchyma, while ficolin- 2 and -3 are predominately identified at low levels in proximity to brain vessels [29]. The levels of ficolin-2 and -3 increase (2.2 and 6.0 times) in brains after TBI [29], but ficolin-1 levels remain unchanged. In mice, only two types of ficolins, called ficolin A (related to human ficolin 2) and ficolin B (related to human ficolin 1), are present $[97,98]$. Our results indicate that after TBI in mice, ficolin $A$ mRNA is upregulated in the early phase, and slight increases in ficolin $B$ mRNA are observed later. The changes in ficolin B are very low in mice, so it may be biologically irrelevant, which fits well with the previous results obtained in humans [29]. The transcriptome database [99] reports that ficolin A is expressed almost exclusively in microglia and macrophages, in contrast to ficolin B, which can be produced by neutrophils [100]. This is in line with our in vitro results showing that ficolin A but not B can be produced by microglial cells. Moreover, the transcriptome database [99] supports our in vitro results showing the lack of ficolin $B$ mRNA in microglia, even after their stimulation. Importantly, recently published findings give evidence that after TBI, ficolin A knockout mice have better outcome scores when compared to wild-type mice [96], suggesting that ficolin A may play a role in TBI.

Based on our results and available literature, we conclude that role of complement in TBI is greater than previously assumed, with long-term changes observed not only in the cortex, but also in the striatum, hippocampus, and thalamus. Especially interesting is a fact that not only $\mathrm{C} 1 \mathrm{q}$, but also $\mathrm{C} 1 \mathrm{~s}$ and $\mathrm{C} 1 \mathrm{r}$ can be produced by activated microglial cells under TBI. Therefore, strategies that modulate microglia/macrophages activation and/or blockade of the C1q complex might represent a promising opportunity for novel, effective therapies in brain damage. As mentioned above, C1-inhibitor has been shown 
to act as an important tool in reducing functional and neuropathological consequences of TBI $[15,17]$. Importantly, this molecule is already available for clinical use in patients suffering from hereditary angioedema [101]. In addition, other novel inhibitors are presently being designed to block $\mathrm{C} 1 \mathrm{q}$ such as a functional $\mathrm{C} 1 \mathrm{q}$ antibody that binds to the globular head domain of $\mathrm{C} 1$ and prevents activation of $\mathrm{C} 1 \mathrm{r} / \mathrm{s}$. Preliminary research indicates that this antibody enters the brain and decreases synapse loss and cognitive dysfunction [72]. In light of our results, it seems that using such a functional C1q antibody in TBI models might contribute to a deeper understanding of pathomechanism and will bring us closer to developing more effective therapy. Currently developed C1r/s inhibitors could also hold promise in future research if brain penetrant compounds would be established. Moreover, our research highlights significant changes in ficolin A not only in the cortex but even in other brain areas following TBI. So far, ficolin A and ficolin 1 have been considered as plasma markers of severity after brain injury, including in clinic [102]. Ficolin 1 is considered as a target for autoimmune diseases therapy [103]. However, further more research is still required to prove the anti-inflammatory effect of anti-ficolin 1 monoclonal antibody in CNS, especially in the light of current results showing the interest of performing such studies in TBI models. Overall, a deeper understanding the role of complement factors and their spatial and temporal fluctuations will be pivotal for development of novel therapeutic strategies for TBI.

\section{Materials and Methods}

\subsection{Animals}

Procedures involving animals and their care were conducted in conformity with institutional guidelines in compliance with national and international laws and policies (prot.9F5F5.81 authorization $\mathrm{n}^{\circ} 753 / 2017-\mathrm{PR}$ ). All animals had free access to food and water and were maintained at a temperature of $22 \pm 2{ }^{\circ} \mathrm{C}$ and a relative humidity of $55 \pm 10 \%$ on a $12 \mathrm{~h}$ light/dark cycle. We used male 9 week old C57BL/6J mice weighing 22-28 g (purchased from Charles River, Calco, Italy). Pregnant C57BL/6J female mice (purchased from Charles River, Cologne, Germany) were used to obtain 1-day-old mouse pups for primary glial cell culture studies.

\subsection{Experimental Traumatic Brain Injury (TBI Model)}

Inhalation anesthesia (isoflurane-induction, $3 \%$ and maintenance, $1.5 \%$ ) in $\mathrm{N}_{2} \mathrm{O} / \mathrm{O}_{2}$ $(70 / 30 \%)$ was used to anesthetize mice that were immobilized in a stereotaxic frame. Animals were exposed to a craniotomy on the left side of the skull and then to TBI through the controlled cortical impact using a previously established procedure $[13,21,22]$. The TBI was performed using a $3 \mathrm{~mm}$ diameter rigid impactor driven by a pneumatic piston rigidly mounted at an angle of $20^{\circ}$ from the vertical plane and applied vertically to the exposed dura mater, between bregma and lambda, over the left parieto-temporal cortex. The impactor velocity of $5 \mathrm{~m} / \mathrm{s}$ and depth of $1 \mathrm{~mm}$ were set, which resulted in severe brain injury. After CCI, craniotomy and scalp stitching were performed. Sham-injured mice were exposed to the same anesthesia and surgery without brain injury. No animals died after surgery. Typical TBI mice present a mean cortical lesion of $17 \mathrm{~mm}^{3} 6$ weeks after injury $[3,96]$.

\subsection{Primary Microglial Cell Cultures}

Primary microglial cell cultures (prepared from the cerebral cortex obtained from newborn C57BL/6J mice) were used to perform in vitro studies, as described in our previous papers [104,105]. The cells were plated in culture medium consisting of high-glucose GlutaMAX ${ }^{\mathrm{TM}}$ DMEM supplemented with $10 \%$ heat-inactivated fetal bovine serum, $0.1 \mathrm{mg} / \mathrm{mL}$ streptomycin and $100 \mathrm{U} / \mathrm{mL}$ penicillin (Gibco, Gaithersburg, MD, USA) on poly-L-lysinecoated $75-\mathrm{cm}^{2}$ culture flasks (at a seeding density of $3 \times 10^{5}$ cells $/ \mathrm{cm}^{2}$ ) and grown in an incubator with a humidified atmosphere $\left(37^{\circ} \mathrm{C}, 5 \% \mathrm{CO}_{2}\right.$ in air). The culture medium was replaced with fresh medium every 4 days. The microglial cells, which were loosely attached 
to the monolayer, were gently harvested by shaking at 70 revolutions per minute (RPM) for $1 \mathrm{~h}$ and then at $90 \mathrm{RPM}$ for $15 \mathrm{~min}$ and then were centrifuged (800 RPM-10 min) on the 16th day of culture. The viability of cells in culture was determined using Trypan blue (Bio-Rad, Warsaw, Poland) exclusion method. The primary microglial cultures were treated with lipopolysaccharide (LPS, $100 \mathrm{ng} / \mathrm{mL}$, Sigma-Aldrich, St. Louis, MO, USA) for $24 \mathrm{~h}$. Cells were seeded at a density of $2 \times 10^{5}$ cells/well on 24 well plates and cultured for $24 \mathrm{~h}$ followed by analysis of the mRNA levels. IBA-1 (microglial marker) was used to assess cell specificity. A minimum essential number of newborn animals were used for culture generation. Although LPS stimulation does not directly imitate TBI-induced inflammation, we decided to use it since it is one of the most widely-used pro-inflammatory factor to study immune response of glial cells. As previously reported [106], some of the genes up-regulated by LPS are also strongly expressed by microglia after TBI, as shown in ex vivo studies. Additionally comparison of LPS stimulation with that obtained using interferon- $\gamma(\mathrm{IFN} \gamma)$ and tumor necrosis factor- $\alpha$ (TNF $\alpha)$ showed that both treatments increased numerous inflammatory genes, however the changes observed after LPS were most pronounced [107].

\subsection{Biochemical Analysis \\ 4.4.1. RT-qPCR}

To assess gene expression, tissue obtained from selected brain ipsilateral areas, including cortex (with all the tissue above the rhinal fissure), striatum, thalamus, and hippocampus, and cell culture lysates were used. Samples from ex vivo experiments were dissected from sham and TBI mice at five time points ( $24 \mathrm{~h}, 4$ days, 7 days, 2 weeks and 5 weeks), immersed in RNA-later (Ambion, Inc, Austin, TX, USA) and frozen at $-80^{\circ} \mathrm{C}$ before use. For RT-qPCR, total RNA was extracted [108] with TRIzol reagent (Invitrogen, Carlsbad, CA, USA) as previously described [109]. The total RNA concentration was measured using a DeNovix DS-11 Spectrophotometer (DeNovix Inc., Wilmington, DE, USA). Reverse transcription was performed on $1000 \mathrm{ng}$ (for tissue) or $500 \mathrm{ng}$ (for cultured cell) of total RNA using Omniscript Reverse Transcriptase (Qiagen Inc., Hilden, Germany) at $37^{\circ} \mathrm{C}$ for $60 \mathrm{~min}$. The resulting cDNA was diluted 1:10 with $\mathrm{H}_{2} \mathrm{O}$. RT-qPCR was performed using Assay-OnDemand TaqMan probes according to the manufacturer's protocol (Applied Biosystems, Foster City, CA, USA) and was run on an iCycler device (BioRad, Hercules, Warsaw, Poland). The following TaqMan primers were used: Mm00446968_m1 (hypoxanthine guanine phosphoribosyl transferase, Hprt), Mm00479862_g1 (allograft inflammatory factor 1, IBA-1), Mm00525305_m1 (transmembrane protein 119, TMEM119), Mm01253033_m1 (glial fibrillary acidic protein, GFAP), Mm00503537_m1 (Cd177), Mm01210556_m1 (oligodendrocyte transcription factor 2, Olig2), Mm01182107_g1 (Cd8), Mm00432142_m1 (complement component 1, q subcomponent, alpha polypeptide, C1qa), Mm00663210_mH (complement component 1, s subcomponent 1, C1s1), Mm04206253_g1 (complement component 1, r subcomponent A, C1ra), Mm01289834_m1 (collectin 11), Mm00484287_m1 (ficolin A), Mm01332438_m1 (ficolin B), Mm00495413_m1 (mannose binding lectin A, MBL-A), and Mm00487623_m1 (mannose binding lectin C, MBL-C). Expression of the Hprt transcript (a housekeeping gene) was quantified to control for variations in the amount of cDNA. The cycle threshold values were calculated automatically using iCycler IQ 3.0 software with the default parameters. The abundance of RNA was calculated as $2^{- \text {(threshold cycle). }}$.

\subsubsection{Western Blotting}

Ipsilateral cortical, striatal, thalamic, and hippocampal tissues harvested $24 \mathrm{~h}$ and 7 days after TBI or sham procedure were used for our study. The tissue was placed in radioimmunoprecipitation assay buffer (RIPA) buffer supplemented with a protease inhibitor cocktail (Sigma-Aldrich, St. Louis, MO, USA). All the samples were cleared by $14,000 \times g$ centrifugation for $30 \mathrm{~min}$ at $4{ }^{\circ} \mathrm{C}$. The total protein concentration was measured using the bicinchoninic acid method. Protein samples were heated for $8 \mathrm{~min}$ at $98{ }^{\circ} \mathrm{C}$ in loading buffer $(4 \times$ Laemmli Buffer, Bio-Rad, Warsaw, Poland). Samples were then 
loaded on $4-15 \%$ Criterion TGX precast polyacrylamide gels (Bio-Rad, Warsaw, Poland) to carry out electrophoresis. Samples were then transferred to Immun-Blot polyvinylidene fluoride (PVDF) Membranes (Bio-Rad, Warsaw, Poland) by semidry transfer (30 min, $25 \mathrm{~V}$ ). Membranes were blocked with 5\% nonfat dry milk (Bio-Rad, Warsaw, Poland) in TBST (Tris-buffered saline with $0.1 \%$ Tween 20 ) for $1 \mathrm{~h}$, washed with TBST buffer, and incubated with the following commercially available primary antibodies overnight at $4{ }^{\circ} \mathrm{C}$ : mouse antiGAPDH (1:5000; Merck, Darmstadt, Germany), rabbit anti-IBA-1 (1:500; Novus Biologicals, Centennial, USA), and rabbit anti-GFAP (1:10,000; Novus Biologicals, Centennial, CO, USA). The membranes were then placed in horseradish peroxidase-conjugated anti-rabbit or anti-mouse secondary antibodies (Vector Laboratories, Burlingame, CA, USA) at a dilution of 1:5000 for $1 \mathrm{~h}$ at room temperature (RT). The primary and secondary antibodies were dissolved in SignalBoost Immunoreaction Enhancer Kit (Merck, Darmstadt, Germany) solutions. Membranes were washed in TBST. Immune complexes were detected by the Clarity Western enhanced chemiluminescence (ECL) Substrate (Bio-Rad, Warsaw, Poland) and visualized using a Fujifilm LAS-4000 Fluor Imager system. Quantification of the bands was performed using the Fujifilm Multi Gauge system. The membranes are available for review in the Supplementary Materials file (Supplementary 1).

\subsubsection{Immunofluorescence and Confocal Analysis}

Immunofluorescence was performed on $20 \mu \mathrm{m}$ coronal sections in the brain ipsilateral cortex. After thorough washing with $0.01 \mathrm{M}$ phosphate-buffered saline (PBS), sections were incubated for $1 \mathrm{~h}$ at RT with blocking solution containing 10\% normal goat serum (NGS) and $0.3 \%$ Triton X-100 and then with rabbit anti-mouse C1q $(1.177 \mathrm{mg} / \mathrm{mL}, 1: 500$; Abcam, Cambridge, UK). Positive cells were stained with an Alexa 488-conjugated goat secondary antibody $(4 \mu \mathrm{g} / \mathrm{mL}$, Life Sciences, Hercules, CA, USA). Sections were then incubated for $1 \mathrm{~h}$ with the following primary antibodies: mouse anti-mouse NeuN $(10 \mu \mathrm{g} / \mathrm{mL}$, 1:250; Merck Millipore; Burlington; MA; USA), goat anti-mouse glial fibrillary acid protein (GFAP, $0.5 \mu \mathrm{g} / \mathrm{mL}, 1: 2000$; Chemicon), or biotin rat anti-mouse Cd45 (0.5 mg/mL; 1:800; BD Bioscience, San Jose, CA, USA) followed by incubation with the appropriate Alexa 546or Alexa 555-conjugated goat secondary antibody $(4 \mu \mathrm{g} / \mathrm{mL}$, Life Sciences, Hercules, CA, USA). Vessels were stained with isolectin IB4-647 (IB-4; $1 \mathrm{mg} / \mathrm{mL}$; Invitrogen, Carlsbad, CA). Cell nuclei were stained with Hoechst ( $1 \mathrm{mg} / \mathrm{mL}$, Invitrogen, Carlsbad, CA, USA). For negative control staining, the primary antibodies were omitted, and no staining was observed. Immunofluorescence images were acquired by an IX81 microscope equipped with a confocal scan unit FV500 with 4 laser lines: $\operatorname{Ar}-\mathrm{Kr}(488 \mathrm{~nm})$, He-Ne red $(646 \mathrm{~nm})$, He-Ne green (532 nm) (Olympus, Tokyo, Japan), and a ultraviolet (UV) diode, using the scanning sequential mode to avoid bleed-through effects. Three-dimensional volumes were acquired over $10 \mu \mathrm{m}$ stacks, with $0.23 \mu \mathrm{m}$ step sizes. Imaris v.6 (Bitplane) and GNU Image Manipulation Program (GIMP) were used to obtain three-dimensional renderings of the images.

\subsection{Statistical Analysis}

Mice were randomly selected for surgery and were assigned across all cages and days. To minimize variability, all surgeries were performed by the same investigator. The results of the RT-qPCR analyses are presented as the normalized averages derived from the threshold cycle. For the tissue study (Figures 1-4 and 9) and the primary cell culture study (Figure 10), the RT-qPCR and western blot results are presented as fold changes relative to the control (sham group (Figures 1-4 and 9); unstimulated cells (Figure 10)). To determine the particular time points x TBI interaction (Figures 1-4 and 9), ex vivo results (mean \pm SEM) were evaluated using two-way ANOVA followed by Bonferroni's multiple comparisons post hoc test. Additionally, the in vitro results (mean $\pm \mathrm{SEM}$ ) were evaluated using a t-test (Figure 10). All statistical analyses were performed with GraphPad Prism ver. 8.1.1 (330) (GraphPad Software, Inc., San Diego, CA, USA). 


\section{Conclusions}

Depending on the elapsed time and brain regions, different cell types, such as neutrophils, Cd8+ cells, astroglia, macrophages, and microglia, play an essential role after TBI. Importantly, our results indicate that initiators of complement system activation in the ipsilateral brain structures may be responsible for cellular activation and chemotaxis. Among the complement initiators, it appears that the $\mathrm{C} 1 \mathrm{q} / \mathrm{C} 1 \mathrm{r} / \mathrm{C} 1 \mathrm{~s}$ complex plays an especially important role after brain damage in all studied brain structures (cortex, striatum, thalamus, and hippocampus). The primary microglial cell culture experiments herein suggest that those cells may be largely responsible for the biosynthesis of the initiators of the classical pathway but contributes very little to the production of lectin pathway initiators. In our opinion, selective targeting of microglia/macrophages and/or the C1q complex and ficolin A may be an effective strategy for human TBI therapy and in other neuroinflammation-related diseases; however, additional studies are required to investigate this hypothesis.

Supplementary Materials: The following are available online at https:/ /www.mdpi.com/1422-006 $7 / 22 / 1 / 45 /$ s1. Western blots details are presented as supplementary material 1 (Supplementary 1).

Author Contributions: Conceptualization, A.C., M.-G.D.S. and J.M.; investigation, A.C., K.C., K.P., M.O., D.M. and J.M.; data curation, A.C., K.C., K.P., M.O. and J.M.; formal analysis, A.C., K.C. and K.P.; methodology, A.C., K.C., K.P., M.O. and D.M.; supervision, M.-G.D.S. and J.M.; project administration, M.-G.D.S. and J.M.; resources, A.C., M.-G.D.S. and J.M.; visualization, A.C., K.C., K.P. and M.O.; funding acquisition, M.-G.D.S. and J.M.; writing—original draft, A.C., K.C., K.P., M.O. and J.M.; writing-review \& editing; A.C., K.C., K.P., M.-G.D.S. and J.M. All authors have read and agreed to the published version of the manuscript.

Funding: This work was supported by ERA-NET-NEURON, JTC 2016: LEAP, NEURON9-FP044 from the following national funding institutions: National Centre for Research and Development (Narodowe Centrum Badań i Rozwoju, ERA-NET NEURON-Cofund/1/LEAP/15/17), Poland and the Italian Ministry of Health (Ministero della Salute), Italy. This work was also supported by statutory funds of the Maj Institute of Pharmacology Polish Academy of Sciences. Maj Institute of Pharmacology Polish Academy of Sciences supported the open access publication.

Institutional Review Board Statement: Istituto di Ricerche Farmacologiche Mario Negri IRCCS, Milano, Italy.

Informed Consent Statement: Not applicable.

Data Availability Statement: Data is contained within the article and supplementary material.

Ethics Statement: The experimental procedures were conducted according to recommendations of the National Institutes of Health, and were approved by the Ethical Committee of the Istituto di Ricerche Farmacologiche Mario Negri IRCCS in conformity with institutional guidelines and in compliance with national and international laws and policies (prot.9F5F5.81 authorization $\mathrm{n}^{\circ}$ 753/2017-PR). According to the 3R policy, the number of animals was reduced to an essential minimum. All the procedures regarding the study design, animal experiments, statistical analysis, and data reporting fulfill the criteria of the Animal Research: Reporting of In Vivo Experiments (ARRIVE) guidelines (https: / / www.nc3rs.org.uk/arrive-guidelines).

Acknowledgments: We thank Katarzyna Popiolek-Barczyk for technical support.

Conflicts of Interest: The authors declare no conflict of interest. 


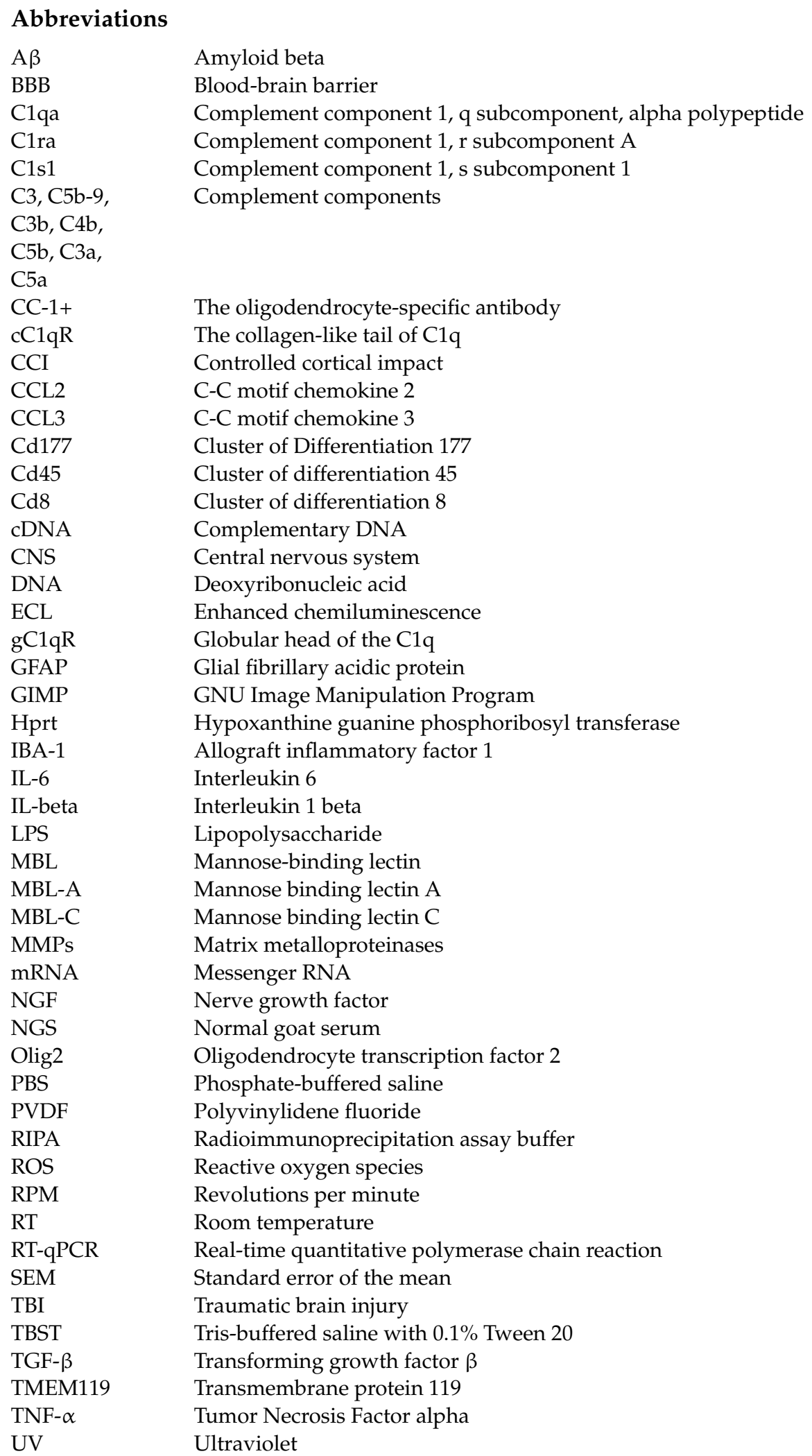

\section{References}

1. Galgano, M.; Toshkezi, G.; Qiu, X.; Russell, T.; Chin, L.; Zhao, L.R. Traumatic brain injury: Current treatment strategies and future endeavors. Cell Transplant. 2017, 26, 1118-1130. [CrossRef] [PubMed]

2. Bellander, B.-M.; Singhrao, S.K.; Ohlsson, M.; Mattsson, P.; Svensson, M. Complement Activation in the Human Brain after Traumatic Head Injury. J. Neurotrauma 2001, 18, 1295-1311. [CrossRef] [PubMed] 
3. De Blasio, D.; Fumagalli, S.; Longhi, L.; Orsini, F.; Palmioli, A.; Stravalaci, M.; Vegliante, G.; Zanier, E.R.; Bernardi, A.; Gobbi, M.; et al. Pharmacological inhibition of mannose-binding lectin ameliorates neurobehavioral dysfunction following experimental traumatic brain injury. J. Cereb. Blood Flow Metab. 2017, 37, 938-950. [CrossRef] [PubMed]

4. $\quad \mathrm{Ng}$, S.Y.; Lee, A.Y.W. Traumatic Brain Injuries: Pathophysiology and Potential Therapeutic Targets. Front. Cell. Neurosci. 2019, 13. [CrossRef] [PubMed]

5. Hammad, A.; Westacott, L.; Zaben, M. The role of the complement system in traumatic brain injury: A review. J. Neuroinflam. 2018, 15. [CrossRef]

6. Liu, Y.-W.; Li, S.; Dai, S.-S. Neutrophils in traumatic brain injury (TBI): Friend or foe? J. Neuroinflam. 2018, 15, 146. [CrossRef]

7. Ciechanowska, A.; Popiolek-Barczyk, K.; Pawlik, K.; Ciapała, K.; Oggioni, M.; Mercurio, D.; De Simoni, M.G.; Mika, J. Changes in macrophage inflammatory protein-1 (MIP-1) family members expression induced by traumatic brain injury in mice. Immunobiology 2020, 225, 1-11. [CrossRef]

8. Zanier, E.R.; Marchesi, F.; Ortolano, F.; Perego, C.; Arabian, M.; Zoerle, T.; Sammali, E.; Pischiutta, F.; De Simoni, M.G. Fractalkine receptor deficiency is associated with early protection but late worsening of outcome following brain trauma in mice. J. Neurotrauma 2016, 33, 1060-1072. [CrossRef]

9. Gao, H.; Han, Z.; Bai, R.; Huang, S.; Ge, X.; Chen, F.; Lei, P. The accumulation of brain injury leads to severe neuropathological and neurobehavioral changes after repetitive mild traumatic brain injury. Brain Res. 2017, 1657, 1-8. [CrossRef]

10. Ramlackhansingh, A.F.; Brooks, D.J.; Greenwood, R.J.; Bose, S.K.; Turkheimer, F.E.; Kinnunen, K.M.; Gentleman, S.; Heckemann, R.A.; Gunanayagam, K.; Gelosa, G.; et al. Inflammation after trauma: Microglial activation and traumatic brain injury. Ann. Neurol. 2011, 70, 374-383. [CrossRef]

11. Johnson, V.E.; Stewart, J.E.; Begbie, F.D.; Trojanowski, J.Q.; Smith, D.H.; Stewart, W. Inflammation and white matter degeneration persist for years after a single traumatic brain injury. Brain 2013, 136, 28-42. [CrossRef] [PubMed]

12. Färber, K.; Cheung, G.; Mitchell, D.; Wallis, R.; Weibe, E.; Schwaeble, W.; Kettenmann, H. C1q, the recognition subcomponent of the classical pathway of complement, drives microglial activation. J. Neurosci. Res. 2009, 87, 644-652. [CrossRef] [PubMed]

13. Zanier, E.R.; Montinaro, M.; Vigano, M.; Villa, P.; Fumagalli, S.; Pischiutta, F.; Longhi, L.; Leoni, M.L.; Rebulla, P.; Stocchetti, N.; et al. Human umbilical cord blood mesenchymal stem cells protect mice brain after trauma. Crit. Care Med. 2011, 39, 2501-2510. [CrossRef] [PubMed]

14. Osier, N.; Dixon, C.E. The Controlled Cortical Impact Model of Experimental Brain Trauma: Overview, Research Applications, and Protocol. Methods Mol. Biol. 2016, 1462, 177-192. [CrossRef]

15. Albert-Weissenberger, C.; Mencl, S.; Schuhmann, M.K.; Salur, I.; Göb, E.; Langhauser, F.; Hopp, S.; Hennig, N.; Meuth, S.G.; Nolte, M.W.; et al. C1-Inhibitor protects from focal brain trauma in a cortical cryolesion mice model by reducing Thrombo-Inflammation. Front. Cell. Neurosci. 2014, 8. [CrossRef]

16. Shaw, M.; Piper, I.; Daley, M. Relationship of a cerebral autoregulatory index with outcome in head injured patients. Acta Neurochir. Suppl. 2008, 102, 33-36. [CrossRef]

17. Longhi, L.; Perego, C.; Ortolano, F.; Zanier, E.R.; Bianchi, P.; Stocchetti, N.; McIntosh, T.K.; De Simoni, M.G. C1-inhibitor attenuates neurobehavioral deficits and reduces contusion volume after controlled cortical impact brain injury in mice. Crit. Care Med. 2009, 37, 659-665. [CrossRef]

18. Gyoneva, S.; Ransohoff, R.M. Inflammatory reaction after traumatic brain injury: Therapeutic potential of targeting cell-cell communication by chemokines. Trends Pharmacol. Sci. 2015, 36, 471-480. [CrossRef]

19. Simon, D.W.; McGeachy, M.J.; Baylr, H.; Clark, R.S.B.; Loane, D.J.; Kochanek, P.M. The far-reaching scope of neuroinflammation after traumatic brain injury. Nat. Rev. Neurol. 2017, 13, 171-191. [CrossRef]

20. Xiong, Y.; Mahmood, A.; Chopp, M. Animal models of traumatic brain injury. Nat. Rev. Neurosci. 2013, 14, 128-142. [CrossRef]

21. Pischiutta, F.; D'Amico, G.; Dander, E.; Biondi, A.; Biagi, E.; Citerio, G.; De Simoni, M.G.; Zanier, E.R. Immunosuppression does not affect human bone marrow mesenchymal stromal cell efficacy after transplantation in traumatized mice brain. Neuropharmacology 2014, 79, 119-126. [CrossRef] [PubMed]

22. Zanier, E.R.; Pischiutta, F.; Riganti, L.; Marchesi, F.; Turola, E.; Fumagalli, S.; Perego, C.; Parotto, E.; Vinci, P.; Veglianese, P.; et al. Bone marrow mesenchymal stromal cells drive protective M2 microglia polarization after brain trauma. Neurotherapeutics 2014, 11, 679-695. [CrossRef] [PubMed]

23. Mao, H.; Lu, L.; Bian, K.; Clausen, F.; Colgan, N.; Gilchrist, M. Biomechanical analysis of fluid percussion model of brain injury. J. Biomech. 2018, 77, 228-232. [CrossRef] [PubMed]

24. Hellewell, S.C.; Ziebell, J.M.; Lifshitz, J.; Morganti-kossmann, M.C. Impact Acceleration Model of Diffuse Traumatic Brain Injury. Methods Mol. Biol. 2016, 1462, 253-266. [CrossRef]

25. Bao, F.; Shultz, S.R.; Hepburn, J.D.; Omana, V.; Weaver, L.C.; Cain, D.P.; Brown, A. A CD11d monoclonal antibody treatment reduces tissue injury and improves neurological outcome after fluid percussion brain injury in rats. J. Neurotrauma 2012, 29, 2375-2392. [CrossRef]

26. Aleem, M.; Goswami, N.; Kumar, M.; Manda, K. Low-pressure fluid percussion minimally adds to the sham craniectomy-induced neurobehavioral changes: Implication for experimental traumatic brain injury model. Exp. Neurol. 2020, 329. [CrossRef]

27. Smith, D.; Brooks, D.; Wohlgehagen, E.; Rau, T.; Poulsen, D. Temporal and Spatial Changes in the Pattern of Iba1 and CD68 Staining in the Rat Brain Following Severe Traumatic Brain Injury. Mod. Res. Inflamm. 2015, 4, 9-23. [CrossRef] 
28. Dyhrfort, P.; Shen, Q.; Clausen, F.; Thulin, M.; Enblad, P.; Kamali-Moghaddam, M.; Lewén, A.; Hillered, L. Monitoring of Protein Biomarkers of Inflammation in Human Traumatic Brain Injury Using Microdialysis and Proximity Extension Assay Technology in Neurointensive Care. J. Neurotrauma 2019. [CrossRef]

29. De Blasio, D.; Fumagalli, S.; Orsini, F.; Neglia, L.; Perego, C.; Ortolano, F.; Zanier, E.R.; Picetti, E.; Locatelli, M.; Stocchetti, N.; et al. Human brain trauma severity is associated with lectin complement pathway activation. J. Cereb. Blood Flow Metab. 2019, 39, 794-807. [CrossRef]

30. Colicos, M.A.; Dixon, C.E. Delayed, selective neuronal death following experimental cortical impact injury in rats: Possible role in memory deficits. Brain Res. 1996, 739, 111-119. [CrossRef]

31. Geddes, D.M.; LaPlaca, M.C.; Cargill, R.S. Susceptibility of hippocampal neurons to mechanically induced injury. Exp. Neurol. 2003, 184, 420-427. [CrossRef]

32. Sato, M.; Chang, E.; Igarashi, T.; Noble, L.J. Neuronal injury and loss after traumatic brain injury: Time course and regional variability. Brain Res. 2001, 917, 45-54. [CrossRef]

33. Mohamed, A.Z.; Corrigan, F.; Collins-Praino, L.E.; Plummer, S.L.; Soni, N.; Nasrallah, F.A. Evaluating spatiotemporal microstructural alterations following diffuse traumatic brain injury. NeuroImage Clin. 2020, 25, 1-15. [CrossRef] [PubMed]

34. Kolaczkowska, E.; Kubes, P. Neutrophil recruitment and function in health and inflammation. Nat. Rev. Immunol. 2013, 13, 159-175. [CrossRef] [PubMed]

35. Zhang, X.; Cheng, R.; Rowe, D.; Sethu, P.; Daugherty, A.; Yu, G.; Shin, H.Y. Shear-sensitive regulation of neutrophil flow behavior and its potential impact on microvascular blood flow dysregulation in hypercholesterolemia. Arterioscler. Thromb. Vasc. Biol. 2014, 34, 587-593. [CrossRef] [PubMed]

36. Pliyev, B.K.; Menshikov, M. Differential effects of the autophagy inhibitors 3-methyladenine and chloroquine on spontaneous and TNF- $\alpha$-induced neutrophil apoptosis. Apoptosis 2012, 17, 1050-1065. [CrossRef]

37. Flygt, J.; Djupsjö, A.; Lenne, F.; Marklund, N. Myelin loss and oligodendrocyte pathology in white matter tracts following traumatic brain injury in the rat. Eur. J. Neurosci. 2013, 38, 2153-2165. [CrossRef]

38. West, E.E.; Kolev, M.; Kemper, C. Complement and the Regulation of T Cell Responses. Annu. Rev. Immunol. 2018, 36, 309-338. [CrossRef]

39. Kolev, M.; Dimeloe, S.; Le Friec, G.; Navarini, A.; Arbore, G.; Povoleri, G.A.; Fischer, M.; Belle, R.; Loeliger, J.; Develioglu, L.; et al. Complement Regulates Nutrient Influx and Metabolic Reprogramming during Th1 Cell Responses. Immunity 2015, 42, $1033-1047$. [CrossRef]

40. West, E.E.; Kunz, N.; Kemper, C. Complement and human T cell metabolism: Location, location, location. Immunol. Rev. 2020, 295, 68-81. [CrossRef]

41. Daglas, M.; Draxler, D.F.; Ho, H.; McCutcheon, F.; Galle, A.; Au, A.E.; Larsson, P.; Gregory, J.; Alderuccio, F.; Sashindranath, M.; et al. Activated CD8+ T Cells Cause Long-Term Neurological Impairment after Traumatic Brain Injury in Mice. Cell Rep. 2019, 29, 1178-1191.e6. [CrossRef] [PubMed]

42. Mracsko, E.; Liesz, A.; Stojanovic, A.; Lou, W.P.K.; Osswald, M.; Zhou, W.; Karcher, S.; Winkler, F.; Martin-Villalba, A.; Cerwenka, A.; et al. Antigen dependently activated cluster of differentiation 8-positive $\mathrm{T}$ cells cause perforin-mediated neurotoxicity in experimental stroke. J. Neurosci. 2014, 34, 16784-16795. [CrossRef] [PubMed]

43. Dent, K.A.; Christie, K.J.; Bye, N.; Basrai, H.S.; Turbic, A.; Habgood, M.; Cate, H.S.; Turnley, A.M. Oligodendrocyte birth and death following traumatic brain injury in adult mice. PLOS ONE 2015, 10. [CrossRef]

44. Mayer, C.A.; Brunkhorst, R.; Niessner, M.; Pfeilschifter, W.; Steinmetz, H.; Foerch, C. Blood Levels of Glial Fibrillary Acidic Protein (GFAP) in Patients with Neurological Diseases. PLoS ONE 2013, 8. [CrossRef] [PubMed]

45. Yang, Z.; Wang, K.K.W. Glial fibrillary acidic protein: From intermediate filament assembly and gliosis to neurobiomarker. Trends Neurosci. 2015, 38, 364-374. [CrossRef] [PubMed]

46. Honda, M.; Tsuruta, R.; Kaneko, T.; Kasaoka, S.; Yagi, T.; Todani, M.; Fujita, M.; Izumi, T.; Maekawa, T. Serum glial fibrillary acidic protein is a highly specific biomarker for traumatic brain injury in humans compared with S-100B and neuron-specific enolase. J. Trauma Inj. Infect. Crit. Care 2010, 69, 104-109. [CrossRef]

47. Kumar, A.; Loane, D.J. Neuroinflammation after traumatic brain injury: Opportunities for therapeutic intervention. Brain. Behav. Immun. 2012, 26, 1191-1201. [CrossRef]

48. Shlosberg, D.; Benifla, M.; Kaufer, D.; Friedman, A. Blood-brain barrier breakdown as a therapeutic target in traumatic brain injury. Nat. Rev. Neurol. 2010, 6, 393-403. [CrossRef]

49. Herndon, J.M.; Tome, M.E.; Davis, T.P. Development and Maintenance of the Blood-Brain Barrier. In Primer on Cerebrovascular Diseases: Second Edition; Elsevier Inc.: New York, NY, USA, 2017; pp. 51-56. ISBN 9780128030585.

50. Pearn, M.L.; Niesman, I.R.; Egawa, J.; Sawada, A.; Almenar-Queralt, A.; Shah, S.B.; Duckworth, J.L.; Head, B.P. Pathophysiology Associated with Traumatic Brain Injury: Current Treatments and Potential Novel Therapeutics. Cell. Mol. Neurobiol. 2017, 37, 571-585. [CrossRef]

51. Lafrenaye, A.D.; Mondello, S.; Wang, K.K.; Yang, Z.; Povlishock, J.T.; Gorse, K.; Walker, S.; Hayes, R.L.; Kochanek, P.M. Circulating GFAP and Iba-1 levels are associated with pathophysiological sequelae in the thalamus in a pig model of mild TBI. Sci. Rep. 2020, 10. [CrossRef] 
52. Makinde, H.M.; Cuda, C.M.; Just, T.B.; Perlman, H.R.; Schwulst, S.J. Nonclassical Monocytes Mediate Secondary Injury, Neurocognitive Outcome, and Neutrophil Infiltration after Traumatic Brain Injury. J. Immunol. 2017, 199, 3583-3591. [CrossRef] [PubMed]

53. Ziegler-Heitbrock, L.; Ancuta, P.; Crowe, S.; Dalod, M.; Grau, V.; Hart, D.N.; Leenen, P.J.M.; Liu, Y.J.; MacPherson, G.; Randolph, G.J.; et al. Nomenclature of monocytes and dendritic cells in blood. Blood 2010, 116. [CrossRef] [PubMed]

54. Li, Q.; Barres, B.A. Microglia and macrophages in brain homeostasis and disease. Nat. Rev. Immunol. 2018, 18, 225-242. [CrossRef] [PubMed]

55. Yin, J.; Valin, K.L.; Dixon, M.L.; Leavenworth, J.W. The Role of Microglia and Macrophages in CNS Homeostasis, Autoimmunity, and Cancer. J. Immunol. Res. 2017, 2017. [CrossRef] [PubMed]

56. Donat, C.K.; Scott, G.; Gentleman, S.M.; Sastre, M. Microglial activation in traumatic brain injury. Front. Aging Neurosci. 2017, 9, 1-20. [CrossRef] [PubMed]

57. Loane, D.J.; Kumar, A. Microglia in the TBI brain: The good, the bad, and the dysregulated. Exp. Neurol. 2016, $275,316-327$. [CrossRef]

58. Bennett, M.L.; Bennett, F.C.; Liddelow, S.A.; Ajami, B.; Zamanian, J.L.; Fernhoff, N.B.; Mulinyawe, S.B.; Bohlen, C.J.; Adil, A.; Tucker, A.; et al. New tools for studying microglia in the mouse and human CNS. Proc. Natl. Acad. Sci. USA 2016, 113, E1738-E1746. [CrossRef]

59. Van Wageningen, T.A.; Vlaar, E.; Kooij, G.; Jongenelen, C.A.M.; Geurts, J.J.G.; Van Dam, A.M. Regulation of microglial TMEM119 and P2RY12 immunoreactivity in multiple sclerosis white and grey matter lesions is dependent on their inflammatory environment. Acta Neuropathol. Commun. 2019, 7, 1-16. [CrossRef]

60. Satoh, J.I.; Kino, Y.; Asahina, N.; Takitani, M.; Miyoshi, J.; Ishida, T.; Saito, Y. TMEM119 marks a subset of microglia in the human brain. Neuropathology 2016, 36, 39-49. [CrossRef]

61. Mulder, S.D.; Nielsen, H.M.; Blankenstein, M.A.; Eikelenboom, P.; Veerhuis, R. Apolipoproteins E and J interfere with amyloid-beta uptake by primary human astrocytes and microglia in vitro. Glia 2014, 62, 493-503. [CrossRef]

62. Morgan, T.E.; Rozovsky, I.; Sarkar, D.K.; Young-Chan, C.S.; Nichols, N.R.; Laping, N.J.; Finch, C.E. Transforming growth factor- $\beta 1$ induces transforming growth factor- $\beta 1$ and transforming growth factor- $\beta$ receptor messenger RNAs and reduces complement C1qB messenger RNA in rat brain microglia. Neuroscience 2000, 101, 313-321. [CrossRef]

63. Neglia, L.; Fumagalli, S.; Orsini, F.; Zanetti, A.; Perego, C.; De Simoni, M.G. Mannose-binding lectin has a direct deleterious effect on ischemic brain microvascular endothelial cells. J. Cereb. Blood Flow Metab. 2019, 40, 1608-1620. [CrossRef]

64. Lynch, N.J.; Willis, C.L.; Nolan, C.C.; Roscher, S.; Fowler, M.J.; Weihe, E.; Ray, D.E.; Schwaeble, W.J. Microglial activation and increased synthesis of complement component C1q precedes blood-brain barrier dysfunction in rats. Mol. Immunol. 2004, 40, 709-716. [CrossRef] [PubMed]

65. Schäfer, M.K.; Schwaeble, W.J.; Post, C.; Salvati, P.; Calabresi, M.; Sim, R.B.; Petry, F.; Loos, M.; Weihe, E. Complement C1q Is Dramatically Up-Regulated in Brain Microglia in Response to Transient Global Cerebral Ischemia. J. Immunol. 2000, 164, 5446-5452. [CrossRef]

66. Fonseca, M.I.; Chu, S.H.; Hernandez, M.X.; Fang, M.J.; Modarresi, L.; Selvan, P.; MacGregor, G.R.; Tenner, A.J. Cell-specific deletion of C1qa identifies microglia as the dominant source of C1q in mouse brain. J. Neuroinflam. 2017, 14, 1-15. [CrossRef] [PubMed]

67. Depboylu, C.; Schäfer, M.K.H.; Schwaeble, W.J.; Reinhart, T.A.; Maeda, H.; Mitsuya, H.; Damadzic, R.; Rausch, D.M.; Eiden, L.E.; Weihe, E. Increase of C1q biosynthesis in brain microglia and macrophages during lentivirus infection in the rhesus macaque is sensitive to antiretroviral treatment with 6-chloro-2' $3^{\prime}$-dideoxyguanosine. Neurobiol. Dis. 2005, 20, 12-26. [CrossRef] [PubMed]

68. Peterson, S.L.; Nguyen, H.X.; Mendez, O.A.; Anderson, A.J. Complement protein C1q modulates neurite outgrowth in vitro and spinal cord axon regeneration in vivo. J. Neurosci. 2015, 35, 4332-4349. [CrossRef]

69. Lui, H.; Zhang, J.; Makinson, S.R.; Cahill, M.K.; Kelley, K.W.; Huang, H.Y.; Shang, Y.; Oldham, M.C.; Martens, L.H.; Gao, F.; et al. Progranulin Deficiency Promotes Circuit-Specific Synaptic Pruning by Microglia via Complement Activation. Cell 2016, 165, 921-935. [CrossRef]

70. Sekar, A.; Bialas, A.R.; De Rivera, H.; Davis, A.; Hammond, T.R.; Kamitaki, N.; Tooley, K.; Presumey, J.; Baum, M.; Van Doren, V.; et al. Schizophrenia risk from complex variation of complement component 4. Nature 2016, 530, 177-183. [CrossRef]

71. Vasek, M.J.; Garber, C.; Dorsey, D.; Durrant, D.M.; Bollman, B.; Soung, A.; Yu, J.; Perez-Torres, C.; Frouin, A.; Wilton, D.K.; et al. A complement-microglial axis drives synapse loss during virus-induced memory impairment. Nature 2016, 534, 538-543. [CrossRef]

72. Hong, S.; Beja-Glasser, V.F.; Nfonoyim, B.M.; Frouin, A.; Li, S.; Ramakrishnan, S.; Merry, K.M.; Shi, Q.; Rosenthal, A.; Barres, B.A.; et al. Complement and microglia mediate early synapse loss in Alzheimer mouse models. Science 2016, 352. [CrossRef]

73. Fonseca, M.I.; Kawas, C.H.; Troncoso, J.C.; Tenner, A.J. Neuronal localization of C1q in preclinical Alzheimer's disease. Neurobiol. Dis. 2004, 15, 40-46. [CrossRef]

74. Klein, M.A.; Kaeser, P.S.; Schwarz, P.; Weyd, H.; Xenarios, I.; Zinkernagel, R.M.; Carroll, M.C.; Verbeek, J.S.; Botto, M.; Walport, M.J.; et al. Complement facilitates early prion pathogenesis. Nat. Med. 2001, 7, 488-492. [CrossRef]

75. Galvan, M.D.; Luchetti, S.; Burgos, A.M.; Nguyen, H.X.; Hooshmand, M.J.; Hamers, F.P.T.; Anderson, A.J. Deficiency in complement C1q improves histological and functional locomotor outcome after spinal cord injury. J. Neurosci. 2008, 28, 13876-13888. [CrossRef] [PubMed] 
76. You, Z.; Yang, J.; Takahashi, K.; Yager, P.H.; Kim, H.H.; Qin, T.; Stahl, G.L.; Ezekowitz, R.A.B.; Carroll, M.C.; Whalen, M.J. Reduced tissue damage and improved recovery of motor function after traumatic brain injury in mice deficient in complement component C4. J. Cereb. Blood Flow Metab. 2007, 27, 1954-1964. [CrossRef]

77. Krukowski, K.; Chou, A.; Feng, X.; Tiret, B.; Paladini, M.S.; Riparip, L.K.; Chaumeil, M.M.; Lemere, C.; Rosi, S. Traumatic brain injury in aged mice induces chronic microglia activation, synapse loss, and complement-dependent memory deficits. Int. J. Mol. Sci. 2018, 19, 3753. [CrossRef] [PubMed]

78. Ten, V.S.; Sosunov, S.A.; Mazer, S.P.; Stark, R.I.; Caspersen, C.; Sughrue, M.E.; Botto, M.; Connolly, E.S.; Pinsky, D.J. C1q-deficiency is neuroprotective against hypoxic-ischemic brain injury in neonatal mice. Stroke 2005, 36, 2244-2250. [CrossRef]

79. Benoit, M.E.; Hernandez, M.X.; Dinh, M.L.; Benavente, F.; Vasquez, O.; Tenner, A.J. C1q-induced LRP1B and GPR6 proteins expressed early in Alzheimer disease mouse models, are essential for the C1q-mediated protection against amyloid- $\beta$ neurotoxicity. J. Biol. Chem. 2013, 288, 654-665. [CrossRef] [PubMed]

80. Thielens, N.M.; Tedesco, F.; Bohlson, S.S.; Gaboriaud, C.; Tenner, A.J. C1q: A fresh look upon an old molecule. Mol. Immunol. 2017, 89, 73-83. [CrossRef]

81. Bossi, F.; Tripodo, C.; Rizzi, L.; Bulla, R.; Agostinis, C.; Guarnotta, C.; Munaut, C.; Baldassarre, G.; Papa, G.; Zorzet, S.; et al. C1q as a unique player in angiogenesis with therapeutic implication in wound healing. Proc. Natl. Acad. Sci. USA 2014, 111, 4209-4214. [CrossRef]

82. Feng, X.; Tonnesen, M.G.; Peerschke, E.I.B.; Ghebrehiwet, B. Cooperation of C1q Receptors and Integrins in C1q-Mediated Endothelial Cell Adhesion and Spreading. J. Immunol. 2002, 168, 2441-2448. [CrossRef] [PubMed]

83. Van Den Berg, R.H.; Faber-Krol, M.C.; Sim, R.B.; Dana, M.R. The first subcomponent of complement, C1q, triggers the production of IL-8, IL-6, and monocyte chemoattractant peptide-1 by human umbilical vein endothelial cells. J. Immunol. 1998, 161, 6924-6930. [PubMed]

84. Navratil, J.S.; Watkins, S.C.; Wisnieski, J.J.; Ahearn, J.M. The Globular Heads of C1q Specifically Recognize Surface Blebs of Apoptotic Vascular Endothelial Cells. J. Immunol. 2001, 166, 3231-3239. [CrossRef] [PubMed]

85. Benoit, M.E.; Tenner, A.J. Complement protein C1q-mediated neuroprotection is correlated with regulation of neuronal gene and microRNA expression. J. Neurosci. 2011, 31, 3459-3469. [CrossRef]

86. Fraser, D.A.; Pisalyaput, K.; Tenner, A.J. C1q enhances microglial clearance of apoptotic neurons and neuronal blebs, and modulates subsequent inflammatory cytokine production. J. Neurochem. 2010, 112, 733-743. [CrossRef]

87. Pisalyaput, K.; Tenner, A.J. Complement component C1q inhibits $\beta$-amyloid- and serum amyloid P-induced neurotoxicity via caspase- and calpain-independent mechanisms. J. Neurochem. 2008, 104, 696-707. [CrossRef]

88. Boone, D.R.; Weisz, H.A.; Willey, H.E.; Torres, K.E.O.; Falduto, M.T.; Sinha, M.; Spratt, H.; Bolding, I.J.; Johnson, K.M.; Parsley, M.A.; et al. Traumatic brain injury induces long-lasting changes in immune and regenerative signaling. PLoS ONE 2019, 14, 1-27. [CrossRef]

89. Munivenkatappa, A.; Agrawal, A. Role of thalamus in recovery of traumatic brain injury. J. Neurosci. Rural Pract. 2016, 7, S76-S79. [CrossRef]

90. Gesuete, R.; Storini, C.; Fantin, A.; Stravalaci, M.; Zanier, E.R.; Orsini, F.; Vietsch, H.; Mannesse, M.L.M.; Ziere, B.; Gobbi, M.; et al. Recombinant C1 inhibitor in brain ischemic injury. Ann. Neurol. 2009, 66, 332-342. [CrossRef]

91. Wagner, S.; Lynch, N.J.; Walter, W.; Schwaeble, W.J.; Loos, M. Differential Expression of the Murine Mannose-Binding Lectins A and $C$ in Lymphoid and Nonlymphoid Organs and Tissues. J. Immunol. 2003, 170, 1462-1465. [CrossRef]

92. Lu, J.; Wu, X.; Teh, B.K. The regulatory roles of C1q. Immunobiology 2007, 212, 245-252. [CrossRef] [PubMed]

93. Vegh, Z.; Kew, R.R.; Gruber, B.L.; Ghebrehiwet, B. Chemotaxis of human monocyte-derived dendritic cells to complement component C1q is mediated by the receptors gC1qR and cC1qR. Mol. Immunol. 2006, 43, 1402-1407. [CrossRef] [PubMed]

94. Longhi, L.; Orsini, F.; De Blasio, D.; Fumagalli, S.; Ortolano, F.; Locatelli, M.; Stocchetti, N.; De Simoni, M.G. Mannose-binding lectin is expressed after clinical and experimental traumatic brain injury and its deletion is protective. Crit. Care Med. 2014, 42, 1910-1918. [CrossRef] [PubMed]

95. Farrar, C.A.; Tran, D.; Li, K.; Wu, W.; Peng, Q.; Schwaeble, W.; Zhou, W.; Sacks, S.H. Collectin-11 detects stress-induced L-fucose pattern to trigger renal epithelial injury. J. Clin. Investig. 2016, 126. [CrossRef]

96. Mercurio, D.; Oggioni, M.; Fumagalli, S.; Lynch, N.J.; Roscher, S.; Minuta, D.; Perego, C.; Ippati, S.; Wallis, R.; Schwaeble, W.J.; et al. Targeted deletions of complement lectin pathway genes improve outcome in traumatic brain injury, with MASP-2 playing a major role. Acta Neuropathol. Commun. 2020, 8, 1-13. [CrossRef]

97. Endo, Y.; Liu, Y.; Kanno, K.; Takahashi, M.; Matsushita, M.; Fujita, T. Identification of the mouse H-ficolin gene as a pseudogene and orthology between mouse ficolins A/B and human L-/M-ficolins. Genomics 2004, 84, 737-744. [CrossRef]

98. Kwon, S.; Kim, M.S.; Kim, D.; Lee, K.W.; Choi, S.Y.; Park, J.; Yeon, H.K.; Lee, Y.; Kwon, H.J. Identification of a functionally relevant signal peptide of mouse ficolin A. J. Biochem. Mol. Biol. 2007, 40, 532-538. [CrossRef]

99. Zhang, Y.; Chen, K.; Sloan, S.A.; Bennett, M.L.; Scholze, A.R.; O’Keeffe, S.; Phatnani, H.P.; Guarnieri, P.; Caneda, C.; Ruderisch, N.; et al. An RNA-sequencing transcriptome and splicing database of glia, neurons, and vascular cells of the cerebral cortex. J. Neurosci. 2014, 34, 11929-11947. [CrossRef]

100. Hunold, K.; Weber-Steffens, D.; Runza, V.L.; Jensenius, J.C.; Männel, D.N. Functional analysis of mouse ficolin-B and detection in neutrophils. Immunobiology 2012, 217, 982-985. [CrossRef] 
101. Riedl, M.A.; Grivcheva-Panovska, V.; Moldovan, D.; Baker, J.; Yang, W.H.; Giannetti, B.M.; Reshef, A.; Andrejevic, S.; Lockey, R.F.; Hakl, R.; et al. Recombinant human C1 esterase inhibitor for prophylaxis of hereditary angio-oedema: A phase 2, multicentre, randomised, double-blind, placebo-controlled crossover trial. Lancet 2017, 390, 1595-1602. [CrossRef]

102. Llull, L.; Thiel, S.; Amaro, S.; Cervera, Á.; Planas, A.M.; Chamorro, Á. Ficolin-1 Levels in Patients Developing Vasospasm and Cerebral Ischemia After Spontaneous Subarachnoid Hemorrhage. Mol. Neurobiol. 2017, 54, 6572-6580. [CrossRef] [PubMed]

103. Katayama, M.; Ota, K.; Nagi-Miura, N.; Ohno, N.; Yabuta, N.; Nojima, H.; Kumanogoh, A.; Hirano, T. Ficolin-1 is a promising therapeutic target for autoimmune diseases. Int Immunol. 2019, 31, 23-32. [CrossRef] [PubMed]

104. Rojewska, E.; Zychowska, M.; Piotrowska, A.; Kreiner, G.; Nalepa, I.; Mika, J. Involvement of Macrophage Inflammatory Protein-1 Family Members in the Development of Diabetic Neuropathy and Their Contribution to Effectiveness of Morphine. Front. Immunol. 2018, 9. [CrossRef] [PubMed]

105. Piotrowska, A.; Kwiatkowski, K.; Rojewska, E.; Makuch, W.; Mika, J. Maraviroc reduces neuropathic pain through polarization of microglia and astroglia-Evidence from in vivo and in vitro studies. Neuropharmacology 2016, 108, 207-219. [CrossRef] [PubMed]

106. Morganti, J.M.; Riparip, L.K.; Chou, A.; Liu, S.; Gupta, N.; Rosi, S. Age exacerbates the CCR2/5-mediated neuroinflammatory response to traumatic brain injury. J. Neuroinflam. 2016, 13. [CrossRef]

107. Lively, S.; Schlichter, L.C. Microglia responses to pro-inflammatory stimuli (LPS, IFN $\gamma+\mathrm{TNF} \alpha$ ) and reprogramming by resolving cytokines (IL-4, IL-10). Front. Cell. Neurosci. 2018, 12. [CrossRef]

108. Chomczynski, P.; Sacchi, N. Single-step method of RNA isolation by acid guanidinium thiocyanate-phenol-chloroform extraction. Anal. Biochem. 1987, 162, 156-159. [CrossRef]

109. Kwiatkowski, K.; Piotrowska, A.; Rojewska, E.; Makuch, W.; Mika, J. The RS504393 Influences the Level of Nociceptive Factors and Enhances Opioid Analgesic Potency in Neuropathic Rats. J. Neuroimmune Pharmacol. 2017, 12, 402-419. [CrossRef] 